\title{
Association of copper levels in the hair with gray matter volume, mean diffusivity, and cognitive functions
}

Hikaru Takeuchi $^{1} \cdot$ Yasuyuki Taki ${ }^{1,2,3} \cdot$ Rui Nouchi $^{4,5,6} \cdot$ Ryoichi Yokoyama $^{7} \cdot$ Yuka Kotozaki $^{8}$. Seishu Nakagawa ${ }^{9,10} \cdot$ Atsushi Sekiguchi ${ }^{2,11} \cdot$ Kunio Iizuka $^{12} \cdot$ Yuki Yamamoto $^{9} \cdot$ Sugiko Hanawa9

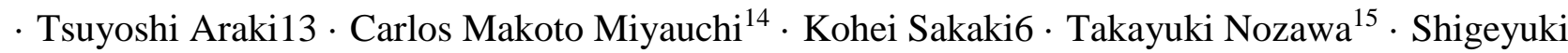
Ikeda $^{16} \cdot$ Susumu Yokota ${ }^{1} \cdot$ Magistro Daniele $^{17} \cdot$ Yuko Sassa $^{1} \cdot$ Ryuta Kawashima $^{1,6,9}$

1. Division of Developmental Cognitive Neuroscience, Institute of Development, Aging and Cancer Tohoku University Sendai Japan

2. Division of Medical Neuroimaging Analysis, Department of Community Medical Supports, Tohoku Medical Megabank Organization Tohoku University Sendai Japan

3. Department of Radiology and Nuclear Medicine, Institute of Development, Aging and Cancer Tohoku University Sendai Japan

4. Creative Interdisciplinary Research Division, Frontier Research Institute for Interdisciplinary Science Tohoku University Sendai Japan

5. Human and Social Response Research Division, International Research Institute of Disaster Science Tohoku University Sendai Japan

6. Department of Advanced Brain Science, Institute of Development, Aging and Cancer Tohoku University Sendai Japan

7. School of Medicine Kobe University Kobe Japan

8. Division of Clinical research, Medical-Industry Translational Research Center Fukushima Medical University School of Medicine Fukushima Japan

9. Department of Human Brain Science, Institute of Development, Aging and Cancer Tohoku University Sendai Japan

10. Division of Psychiatry Tohoku Medical and Pharmaceutical University Sendai Japan

11. Department of Behavioral Medicine National Institute of Mental Health, National Center of Neurology and Psychiatry Tokyo Japan

12. Department of Psychiatry Tohoku University Graduate School of Medicine Sendai Japan

13. ADVANTAGE Risk Management Co., Ltd Tokyo Japan

14. Department of Language Sciences, Graduate School of Humanities Tokyo Metropolitan University Tokyo Japan

15. Collaborative Research Center for Happiness Co-Creation Society through Intelligent Communications Tokyo Institute of Technology Tokyo Japan

16. Department of Ubiquitous Sensing, Institute of Development, Aging and Cancer Tohoku University Sendai Japan

17. Department of Sport Science, School of Science and Technology Nottingham Trent University Nottingham UK 


\begin{abstract}
Although copper plays a critical role in normal brain functions and development, it is known that excess copper causes toxicity. Here we investigated the associations of copper levels in the hair with regional gray matter volume (rGMV), mean diffusivity (MD), and cognitive differences in a study cohort of 924 healthy young adults. Our findings showed that high copper levels were associated mostly with low cognitive abilities (low scores on the intelligence test consisting of complex speed tasks, involving reasoning task, a complex arithmetic task, and a reading comprehension task) as well as lower reverse Stroop interference, high rGMV over widespread areas of the brain [mainly including the bilateral lateral and medial parietal cortices, medial temporal structures (amygdala, hippocampus, and parahippocampal gyrus), middle cingulate cortex, orbitofrontal cortex, insula, perisylvian areas, inferior temporal lobe, temporal pole, occipital lobes, and supplementary motor area], as well as high MD of the right substantia nigra and bilateral hippocampus, which are indicative of low density in brain tissues. These results suggest that copper levels are associated with mostly aberrant cognitive functions, greater

rGMV in extensive areas, greater MD (which are indicative of low density in brain tissues) in subcortical structures in the healthy young adults, possibly reflecting copper's complex roles in neural mechanisms.
\end{abstract}

Keywords Copper $\cdot$ Regional gray matter volume $\cdot$ Mean diffusivity $\cdot$ Cognitive functions 


\section{Introduction}

Copper $(\mathrm{Cu})$ is an essential trace element that plays an important role in humans. Copper serves as a cofactor for several enzymes, such as cytochrome oxidase, $\mathrm{CuZu}$-superoxide dismutase, lysine oxidase, dopamine- $\beta$-hydroxylase, and ceruloplasmin (Paris et al. 2001). On the one hand, $\mathrm{Cu}$ is essential for optimal antioxidant defense, and $\mathrm{Cu}$ deficiency inhibits the body's ability to deal with oxidative stress through decreased capacity of producing the antioxidant superoxide dismutase (Gaetke and Chow 2003). On the other hand, in the brain, copper plays an important role in the production of neurotransmitters, and the enzyme that converts dopamine into norepinephrine is dependent on $\mathrm{Cu}$ (Friedman and Kaufman 1965). Further, animals with dietary copper deficiency exhibit reduced noradrenalin and dopamine concentrations (Hunt 1980). Ceruloplasmin catalyzes the oxidation of the biogenic amines noradrenaline and serotonin (Frieden 1980). $\mathrm{Cu}$ is required for brain development, and mammals with $\mathrm{Cu}$ deficiency during development exhibit smaller brains (Everson et al. 1967) and reduced synthesis of brain tissues (Krejpcio et al. 1997). Further, even a very small $\mathrm{Cu}$ deficiency disturbs the maturation of the hippocampus and dentate gyrus (Hunt and Idso 1995), and copper protects against neuronal death caused by abnormal hyperactivity (Hashimoto 2008). In contrast, $\mathrm{Cu}$ is a redox-active transition metal, excessive $\mathrm{Cu}$ is supposed to initiate oxidative damage, and high $\mathrm{Cu}$ concentrations may cause increased oxidative damage to lipids, proteins, and DNA and contribute to neurodegenerative disorders (Gaetke and Chow 2003). In particular, $\mathrm{Cu}$ neurotoxicity has been investigated, and $\mathrm{Cu}$ has been suggested to play an important role in neurodegeneration (Paris et al. 2001). A previous study has suggested that $\mathrm{Cu}$ neurotoxicity is partly dependent on the reaction between dopamine and $\mathrm{Cu}$, including the formation of $\mathrm{Cu}$-dopamine complexes with concomitant dopamine oxidation, which generates the substance responsible for the degeneration of dopaminergic neurons in the substantia nigra (SeguraAguilar et al. 2001) where $\mathrm{Cu}$ accumulates with aging (Zecca et al. 2005). Further, the association between neurotoxicity and copper has attracted attention, particularly in relation to Alzheimer's disease, and numerous animal, human experimental, clinical, and observational studies have been devoted to this issue (for reviews, refer to Brewer 2009, 2012; Loef and Walach 2012; Squitti et al. 2014a; Pal et al. 2015). Among such studies, an animal study has shown that among rabbits with high cholesterol levels, a small amount of copper leads to learning disability and accumulation of amyloid beta in the hippocampus and temporal lobe (Hashimoto 2008). Previous human physiological studies have found that greater $\mathrm{Cu}$ levels are associated with lower testosterone levels (Chang et al. 2011). Moreover, high $\mathrm{Cu}$ levels in the body are associated with learning disabilities, juvenile delinquency, schizophrenia, and autism (Rimland and Larson 1983; Rahman et al. 2009; Priya and Geetha 2011). Further, among studies relevant to Alzheimer's disease, a large epidemiological study has found that among humans with high blood cholesterol levels, high $\mathrm{Cu}$ levels are associated with accelerated age-related cognitive decline (Morris et al. 2006). The body copper level is inversely related to lower cognitive function in older adults (Salustri et al. 2010), and patients with Alzheimer's disease show elevated hair copper levels (Koc et al. 2015) as well as greater free copper levels in blood (Squitti et al. 2014b). Further, a greater serum free copper level is associated with an unfavorable prognosis of cognitive function in patients with Alzheimer's disease (Squitti et al. 2009). A neuroimaging study has found that childhood exposure to lead (a mineral known for its neurotoxicity) leads to decreased regional gray matter volume rGMV in widespread regions of the brain (Cecil et al. 2008). Despite these previous studies, the following points have not been investigated: 
(a) The associations between $\mathrm{Cu}$ levels in the body and cognitive functions among a large cohort of young adults.

(b) The associations between $\mathrm{Cu}$ levels in the body and brain structural properties among a large cohort of young adults.

The purpose of this study was to investigate these issues. For this purpose, we utilized a wide range of cognitive tests, regional gray matter volume (rGMV) and mean diffusivity (MD), and determined hair $\mathrm{Cu}$ levels in a relatively large cohort of young adults. rGMV and MD are both frequently assessed in the investigations of the long-term effects of environmental factors such as the effects of childhood exposure to environmental factors, including metals, in later life (Cecil et al. 2008; for review of cases of rGMV, see; Takeuchi and Kawashima 2016; Takeuchi et al. 2016a). As described above, despite $\mathrm{Cu}$ 's critical role in neurophysiology and development, an accumulated body of evidence has suggested that unless there is a deficit in $\mathrm{Cu}$ levels, an elevated $\mathrm{Cu}$ level is associated with aberrant neurocognitive conditions. Thus, we hypothesized that among normal young adults in developed countries, high $\mathrm{Cu}$ levels are associated with (a) diminished cognitive functions such as reading and arithmetic abilities due to the abovementioned associations of greater copper levels and learning disabilities (Rimland and Larson 1983). Also, excess $\mathrm{Cu}$ may be associated with (a) even basic cognitive abilities such as working memory capacity and executive function, consistent with the abovementioned associations of high copper levels with age-related cognitive decline, psychiatric diseases, and developmental disorders (Morris et al. 2006; Rahman et al. 2009; Priya and Geetha 2011); (b) reduced cognitive abilities, traits and states related to dopaminergic functions, such as creativity measured by divergent thinking, extraversion, novelty seeking, and state of vigor (for summary, see Takeuchi et al. 2013c); and (c) aberrant brain structure, such as lower rGMV and greater MD (indicative of lower tissue density) (Johansen-Berg et al. 2012), particularly in the substantia nigra and hippocampus.

\section{Methods}

\section{Subjects}

The present study, which is a part of an ongoing project to investigate the association between brain imaging, cognitive function, and aging, included 924 healthy, right-handed individuals (563 men and 361 women) from whom the data necessary for whole brain analyses involving Cu levels were collected. The mean age of the subjects was 20.7 years [standard deviation (SD), 1.8; age range: 18-27 years old]. All subjects were university students, postgraduates, or university graduates of less than 1 year's standing. All subjects had normal vision and none had neurological or psychiatric illness, and this has been confirmed by a self-report. Therefore, we do not consider our sample includes typically neurologically pathological sample. In this study, we recruited subjects who were not taking drugs without specifying details of types of drugs through ads. But still sometimes, some subjects who were taking drugs applied and during the selection process after application, whereas subjects who were taking drugs for brain diseases were excluded, subjects who were taking drugs used in everyday lives such as the drugs for cold, allergy, and contraceptives in the selfreport were not removed. Handedness was evaluated using the Edinburgh Handedness Inventory (Oldfield 1971). For details of subjects' information, see "Supplemental Methods". For the limitation of this study related to subjects' characteristics, see "Supplemental Discussion". 


\section{Hair acquisition and hair mineral analysis}

As summarized in previous studies (Priya and Geetha 2011; Takeuchi et al. 2013c), hair mineral analysis serves as the best indicator of mineral levels in the body and has gathered considerable interest in multiple fields (Lech 2002). Hair is recognized as a potential repository of all elements that enter the body, and mineral levels in the hair indicate the mineral composition accumulated over several months to years (Priya and Geetha 2011). Correlations exist between the concentrations of basic elements in the hair and in the body (Chłopicka et al. 1998; Kedzierska 2003). Hair mineral analysis has advantages over other methods, such as blood and urine analyses, in investigating mineral levels in the body because mineral levels in the hair are not subjected to rapid fluctuations of mineral intake and have long-term stability (Ayodele and Bayero 2009). Scalp hair samples (approximately 4-cm length, 0.1-g weight) were collected from each subject, with the hair cut as close to the scalp as possible. The hair samples were sent to La Belle Vie research laboratory and analyzed by established methods, as described previously (Takeuchi et al. 2013c). The length of the hair sample was prescribed by the company and it is a standard procedure. For details, see Supplemental Methods.

There is continuing debate regarding whether hair or blood sampling is more appropriate for investigation of the effects of body copper levels (Wilson 2003). New analytic methods and good practice have improved the precision of hair mineral analysis (Bass et al. 2001). Well controlled changes in copper intake substantially changed hair copper level but not serum copper level in humans (Turnlund et al. 2004). Through experiments on pigs, hair copper was substantially increased when the dietary copper level was increased (Castell and Bowland 1968); hair copper concentration has been found to reflect liver copper concentration in pigs (Jacob et al. 1978). A previous study robustly showed that hair copper levels of children in the city near copper smelter where the levels in water and snow far exceeded existing standards were substantially greater than those of children in the control cities, whereas this effect was not observed for blood copper levels. A previous study showed that 24-h urine copper output following oral chelation with D Penicillamine was strongly correlated with hair copper level, suggesting the validity of "hair mineral analysis" as an accurate monitor of the total body copper load (Nolan 1983). Blood and tissue testing are different and provide valuable information. Other than practical easiness for sampling, hair mineral analyses have the following advantages in measuring long-term body copper loading when properly measured: Hair sampling provides long-term copper loading that is unaffected by daily events and is suitable for the investigation of long-term effects of the copper level (Wilson 2003). Serum mineral levels are maintained at the expense of the tissues even in serious illnesses (Wilson 2003). Excess minerals, including toxic metals, are quickly removed from blood and deposited in tissues including hair (Wilson 2003).

\section{Psychological measures}

Following neuropsychological tests and questionnaires were administered. These tests are described in this subsection and were largely reproduced from our previous studies (Takeuchi et al. 2013a, 2015d). [A] A (computerized) digit span task, which is a working memory task (for details, see Takeuchi et al. 2011b). [B] RAPM (Raven 1998), a non-verbal reasoning task and representative measure of general intelligence. For more details, see our previous study (Takeuchi et al. 2010). [C] 
Tanaka B-type intelligence test (Tanaka et al. 2003) type 3B (TBIT). This non-verbal mass intelligence test, used for 3rd-year junior high school and older examinees, does not include story problems but uses figures, single numbers, and letters as stimuli. In all subtests, the subjects have to solve as many problems as possible before a certain time (a few minutes), meaning these are complex cognitive speed tasks. For more details, see our previous study (Takeuchi et al. 2013a). There are three subfactors, namely the perception factor, the spatial relation factor, and the reasoning factor. The perception factor measures simple processing speed. The spatial relation factor measures spatial abilities to relate different things. The reasoning factor of TBIT measures reasoning abilities. [D] Arithmetic tasks. These tests measure multiplication performance consisting of two forms of one-digit times one-digit multiplication problems (a simple arithmetic task with numbers between 2 and 9) and two forms of two-digit times two-digit multiplication problems (a complex arithmetic task with numbers between 11 and 19). The two forms of each task are same, but the numbers used in the problems are ordered differently. Each form of the simple and complex arithmetic tasks has to be completed in 30 and $60 \mathrm{~s}$, respectively. [E] The Stroop task (Hakoda's version) (Hakoda and Sasaki 1990), which measures response inhibition and impulsivity. Hakoda's version is a matching-type Stroop task requiring subjects to check whether their chosen answers are correct, unlike the traditional oral naming Stroop task. The test consists of two control tasks (WordColor and Color-Word tasks), a Stroop task, and a reverse Stroop task. Reverse Stroop and Stroop interference rates are calculated from these. See our previous study for details (Takeuchi et al. 2015c).[F] Reading comprehension task. This task was developed by Kondo et al. (2003). For more details on this test, such as how it was developed and its validity, please refer to Kondo et al. (2003) and our previous study (Takeuchi et al. 2015d). [G] S-A creativity test. Creativity measured by divergent thinking was measured using the S-A creativity test (Society_For_Creative_Minds 1969). $[\mathrm{H}]$ The motivational status of the preceding 1 week for each subject was measured using the Vigor subscale of shortened Japanese version (Yokoyama 2005) of the Profile of Mood States psychological rating scale (McNair et al. 1992). [I] Novelty seeking score on a Japanese version (Kijima et al. 1996) of the Temperament Character Inventory (Cloninger et al. 1993), which was used to measure novelty seeking; [J] Extraversion scale on a Japanese version of the NEO FiveFactor Inventory (NEO-FFI) (Costa and McCrae 1992), which was used to measure extraversion.

\section{Image acquisition}

The methods for MR image acquisition were described in our previous study and reproduced below (Takeuchi et al. 2012). All MRI data acquisition was performed using a 3-T Philips Achieva scanner. High-resolution T1-weighted structural images (T1WIs: $240 \times 240$ matrix, TR = $6.5 \mathrm{ms,}$ $\mathrm{TE}=3 \mathrm{~ms}, \mathrm{FOV}=24 \mathrm{~cm}$, slices $=162$, slice thickness $=1.0 \mathrm{~mm}$ ) were collected using a magnetizationprepared rapid gradient echo sequence. Diffusion-weighted data were acquired using a spinecho EPI sequence $\left(\mathrm{TR}=10,293 \mathrm{~ms}, \mathrm{TE}=55 \mathrm{~ms}, \mathrm{FOV}=22.4 \mathrm{~cm}, 2 \times 2 \times 2 \mathrm{~mm}^{3}\right.$ voxels, 60 slices, SENSE reduction factor $=2$, number of acquisitions $=1$ ). The diffusion weighting was isotropically distributed along 32 directions $\left(b\right.$ value $\left.=1000 \mathrm{~s} / \mathrm{mm}^{2}\right)$. Additionally, three images with no diffusion weighting ( $b$ value $=0 \mathrm{~s} / \mathrm{mm} 2)(b=0$ images) were acquired, using a spin-echo EPI sequence $\left(\mathrm{TR}=10,293 \mathrm{~ms}, \mathrm{TE}=55 \mathrm{~ms}, \mathrm{FOV}=22.4 \mathrm{~cm}, 2 \times 2 \times 2 \mathrm{~mm}^{3}\right.$ voxels, 60 slices $)$. FA and MD maps were calculated from the collected images using a commercially available diffusion tensor analysis package on the MR console. For more details, see "Supplemental Methods". Descriptions in this subsection were mostly reproduced from a previous study using similar 
methods (Takeuchi et al. 2016a). Quality of the all types of the obtained imaging data was checked by visual inspection and images of low quality were not used in this project.

\section{Pre-processing of structural data}

$\mathrm{MD}$, measured using diffusion tensor imaging, is a direction- independent measure of how water molecules can freely move. MD is considered to reflect the amount of tissue in the brain, which prevents the free movement of water, and differences in MD may reflect tissue changes, such as astrocyte swelling, synaptic changes, dendritic spine changes, and angiogenesis; differences in MD are also sensitive to neural plasticity (Johansen-Berg et al. 2012; Sagi et al. 2012; Takeuchi et al. 2016a). MD in the dopaminergic system's areas (MDDS) is sensitive to the pathology of dopaminergic systems compared with other imaging modalities (Parkinson's disease) (Seppi et al. 2004; Péran et al. 2010). MDDS is sensitive to treatment with dopamine agonists used to manage this pathology (Razek et al. 2011) as well as to cognitive states and traits associated with the function of the dopaminergic system (Takeuchi et al. 2015a, 2016b). Preprocessing of the structural data was performed using Statistical Parametric Mapping software (SPM12; Wellcome Department of Cognitive Neurology, London, UK) implemented in Matlab (Mathworks Inc., Natick, MA, USA). Using the new segmentation algorithm and the diffeomorphic anatomical registration through exponentiated Lie algebra (DARTEL) registration process implemented in SPM12, the T1weighted structural images of each individual were segmented and normalized to the Montreal Neurological Institute $(\mathrm{MNI})$ space to generate images with $1.5 \times 1.5 \times 1.5 \mathrm{~mm} 3$ voxels. In addition, we performed a volume change correction (modulation) (Ashburner and Friston 2000). Subsequently, the generated rGMV images were smoothed by convolving them with an isotropic Gaussian kernel of $8 \mathrm{~mm}$ full width at half maximum (FWHM). For a full description of these procedures, see the "Supplemental Methods". The description in this paragraph was mostly reproduced from our previous study that used the same method (Takeuchi et al. 2017).

Preprocessing and analysis of imaging data were performed using SPM8 implemented in Matlab. Basically, we normalized MD images of subjects with previously validated diffeomorphic anatomical registration through exponentiated lie algebra (DARTEL)-based registration process method that utilizes the FA signal distribution within the white matter area in the normalization procedure to give images with $1.5 \times 1.5 \times 1.5 \mathrm{~mm}^{3}$ voxels; then tissues that are not likely to be gray or white matter were carefully removed and smoothed by convolving them with an isotropic Gaussian kernel of 8-mm full width at half maximum. For details, see "Supplemental Methods". The description in this subsection was mostly reproduced from our previous study that used the same method (Takeuchi et al. 2016b). This method can remove partial volume effects of CSF through thorough removal of CSF areas and achieve accurate normalization within the white matter areas by utilizing the FA signal distribution within the white matter area in the normalization procedure. The congruence of findings obtained by tract-based spatial statistics and those obtained by our preprocessing method was shown in our previous study (Takeuchi et al. 2013b). One of the strengths of our preprocessing method is the ability to obtain MD signals in gray matter areas, particularly subcortical regions, which are known to be important in a wide range of studies (Takeuchi and Kawashima, in press).

\section{Whole-brain statistical analysis}


We investigated if the rGMV was associated with individual differences in the hair copper level. The statistical analyses of imaging data were performed with SPM8. In these analyses, we performed a whole-brain multiple regression analysis. These analyses were performed with sex, age, and total intracranial volume (TIV) that was calculated as described previously (Hashimoto et al. 2015), self-reported eight, self-reported weight, and body mass index (BMI), which was calculated from the self-reported height and self-reported weight and $\mathrm{Cu}$ levels in the hair. We included only voxels with an rGMV signal intensity of $>0.05$ for all participants. We used SPM12 for VBM preprocessing and SPM8 for statistical analyses because of the compatibility of the software that we used for permutation-based statistics described below and of the script we used for the statistical analyses. If permutation tests were used, the results were not affected by the version of SPM. The investigation of the associations between regional MD and $\mathrm{Cu}$ levels in the hair was performed using a wholebrain multiple regression analysis. The statistical model was same as that of rGMV, except that the whole-brain multiple regression analysis for MD did not include TIV as a covariate. The analyses were limited to the gray + white matter mask, which was created as described above. A multiple comparison correction was performed using threshold-free cluster enhancement (TFCE) (Smith and Nichols 2009) with randomized (5,000 permutations) nonparametric testing using the TFCE toolbox (http://dbm.neuro uni-jena.de/tfce/). We applied a threshold of FWE corrected at $P<0.05$.

\section{Regions of interest (ROI) analyses of the associations between Cu levels of the hair and MD}

We employed ROI approaches to determine the MD of the bilateral substantia nigra and of the bilateral hippocampus and $\mathrm{Cu}$ levels in the hair. The reasons for focusing on these anatomical areas are described in the "Introduction" section. The mean MD values of the left and right substantia nigraand left and right hippocampus were extracted. For details, see "Supplemental Methods".

\section{Statistical analyses of non-whole brain analyses}

The associations were tested using multiple regression analyses. The dependent variable was the mean MD in one of the ROIs or cognitive variables that were cited in the subsection "Psychological measures". Independent variables comprised sex, age, self-reported height, self-reported weight, and BMI that was calculated from the self-reported height and selfreported weight, and Cu levels in the hair. In these analyses, results with a threshold of $P<0.05$ were considered to be statistically significant after correcting for the false discovery rate (FDR) using the graphically sharpened method (Benjamini and Hochberg 2000). This correction for multiple comparisons was performed among 19 non-whole brain multiple regression analyses (15 dependent variables of psychological measures and 4 dependent variables of MD). Although the linear regression analyses showed mostly significant results, from the information presented in the Introduction, one might expect a nonlinear relationship. According to our previous study (Taki et al. 2011), to analyze whether the linear or quadratic function best fits the trajectory of the mean MD in one of the ROIs or cognitive variables that were cited in the subsection of Psychological measures with $\mathrm{Cu}$ levels in the hair, the correlations of these associations were estimated using linear and quadratic functions in each ROI. However, these results did not achieve the best possible fit for quadratic functions in an expected way. Further, these analyses must be performed without covariates that serve as a reference. Therefore, we only reported the results of multiple regression analyses showing significant results. 
Further, it is known both $\mathrm{Cu}$ and iron have similar binding proteins in cerebral tissue and they affect each other during uptake (Fox 2003; Ha et al. 2018); therefore, the iron level might affect the present results. To exclude such possibilities, we additionally performed non-whole brain multiple regression analyses including hair iron level as an additional covariate. Here to avoid double dipping procedures in whole brain multiple regression analyses, for GMV analyses, we used total GMV as a dependent variable. We confirmed that the addition of hair iron level as a covariate did not affect substantially influence the strengths of significant associations. For these methods and results, see "Supplemental Methods", "Supplemental Results", and "Supplemental Table 1".

We did not perform mediation analyses to see if neural mechanisms mediate the associations between hair copper levels and cognitive functions and between hair copper levels and neural mechanisms. We present the correlations among hair copper levels and significant psychological and neural correlates of hair copper levels after correcting for confounding variables in Supplemental Table 2 (rGMV of the large cluster of significant correlations was replaced by total GMV to avoid double-dippingprocedures) (Kriegeskorte et al. 2009) Since hair copper levels mostly negatively correlated with cognitive functions as presented in "Results", if neural mechanisms mediate the associations of hair copper levels with cognitive functions, neural mechanisms should correlate with hair copper levels and cognitive functions in opposite ways. Mostly, there were no such significant correlations, although there is one such correlation, and total GMV negatively correlated with complex calculation performance and positively correlated with hair copper level; p-value was only marginally significant and among many statistical tests, it is difficult to gage the significance of the findings. This could be due to the potentially complex mechanisms of the associations of copper levels with neural mechanisms (see the third paragraph of "Discussion").

\section{Results}

\section{Basic data}

The mean and standard deviation for age, general intelligence test score, and hair Cu levels (raw and $\log )$ are presented in Table 1. Average $( \pm \mathrm{SD})$ raw hair copper level was $24.01( \pm 31.28) \mu \mathrm{g} / \mathrm{g}$ in males and $27.34( \pm 18.72) \mu \mathrm{g} / \mathrm{g}$ in females. In most of the studies on normal subjects, the average hair copper levels ranged from 10 to 35 or $40 \mu \mathrm{g} / \mathrm{g}$; therefore, our samples fall within a normal range (Sakai 1970), and this average value is well within the reference range for the hair copper levels of normal subjects reported in a previous review (Mikulewicz et al. 2013) and similar to the value $(22.4 \mu \mathrm{g} / \mathrm{g})$ for young Japanese adults measured by the same company (La Belle Vie Inc, Tokyo, Japan). The distribution of the logarithms of $\mathrm{Cu}$ levels in the hair for men and women are presented in Supplemental Fig. 1.

\section{Psychological analyses of the correlations between $\mathrm{Cu}$ levels in the hair and individual cognitive differences}

Psychological analyses revealed that after correcting for confounding variables and multiple comparisons, $\mathrm{Cu}$ levels in the hair significantly and negatively correlated with the total intelligence score of TBIT, the reasoning factor of TBIT, complex arithmetic, reverse Stroop interference, and a reading comprehension task, but not with the other cognitive functions, traits, and states that are 
related to dopaminergic functions (Fig. 1). The results of all statistical analyses are presented in Table 2.

\section{Analyses of the correlations between $\mathrm{Cu}$ levels in the hair and rGMV}

The whole-brain multiple regression analysis showed that $\mathrm{Cu}$ levels in the hair significantly and positively correlated with rGMV in widespread areas, mainly including the bilateral lateral and medial parietal cortices, medial temporal structures (amygdala, hippocampus, and parahippocampal gyrus), middle cingulate cortex, orbitofrontal cortex, insula, perisylvian areas, inferior temporal lobe, temporal pole, occipital lobes, and supplementary motor area (Fig. 2; Table 3).

\section{Analyses of the correlations between $\mathrm{Cu}$ levels in the hair and MD}

The whole-brain multiple regression analysis showed that $\mathrm{Cu}$ levels in the hair did not significantly correlate with MD in any of the brain regions. ROI analyses of the bilateral substantia nigra and bilateral hippocampus showed that $\mathrm{Cu}$ levels in the hair positively and significantly correlated with the MD of the right substantia nigra (Fig. 3; Table $4 ; \beta=0.082, t=2.624, p=0.009$ ), MD of the right hippocampus (Fig. 3; Table 4; $\beta=0.069, t=2.127, p=0.034$ ), and MD of the left hippocampus (Fig. 3; Table 4; $\beta=0.068, t=2.131, p=0.034$ ), but not with the MD of the left substantia nigra (Fig. 3; Table $4 ; \beta=-0.010, t=-0.303, p=0.762$ ).

\section{Discussion}

In the present study, the associations of $\mathrm{Cu}$ levels in the hair with a wide range of cognitive differences, rGMV, and MD were investigated among a relatively large cohort of young adult subjects in a developed country. Partially consistent with our hypothesis, our novel findings showed that high $\mathrm{Cu}$ levels were associated with a low total intelligence score of tests comprising time tasks, reasoning factors of this test, complex arithmetic tasks, and a reading comprehension task. However, partially inconsistent with our hypothesis, high $\mathrm{Cu}$ levels were associated with reduced reverse Stroop interference (indicator of the ability to resolve cognitive interference). Further, partially consistent with our hypothesis, high $\mathrm{Cu}$ levels were associated with high MD of the right substantia nigra and bilateral hippocampus, which were indicative of low densities of various neural tissues in the regions described below. However, partially inconsistent with our hypothesis, high $\mathrm{Cu}$ levels were associated with high rGMVs in widespread areas, mainly including the bilateral lateral and medial parietal cortices, medial temporal structures (including the hippocampus), middle cingulate cortex, orbitofrontal cortex, insula, perisylvian regions, inferior temporal lobe, temporal pole, occipital lobes, and supplementary motor areas. Finally, inconsistent with our hypothesis, $\mathrm{Cu}$ levels did not show significant relationships with cognitive abilities, traits, and states associated with dopaminergic functioning. In this study, there are few possible limitations and possible confounding factors that may be considered before discussing specific results. (1) We believe it is unlikely that the present imaging results were caused by the magnetic properties of $\mathrm{Cu}$ in the brain. For example, the physiological $\mathrm{Cu}$ concentrations in the brain are too small to produce a detectable MR contrast (Bai et al. 2013). Further, $\mathrm{Cu}$ has a paramagnetic property, and the accumulation of paramagnetic minerals may lead to decreased signals in MD images and related images 
(Chandarana et al. 2012). However, the present study showed a high MD signal in subjects with high $\mathrm{Cu}$ levels in the hair. (2) The present cohort comprised educated people who were young and healthy. which is a common caveat of studies on college students (Jung et al. 2010) in developed countries. Among subjects with symptoms of $\mathrm{Cu}$ deficiency and subjects with high cholesterol levels, where higher copper intake is associated with cognitive decline (Morris et al. 2006), how $\mathrm{Cu}$ levels associate with cognitive and neural variables may differ in such samples. Future studies need to investigate these issues. (3) Further, $\mathrm{Cu}$ is involved in neurotransmitter synthesis and to assess the relevant associations of such physiological properties (Paris et al. 2001), the measures that can specifically tap these acute changes, such as blood $\mathrm{Cu}$ level, and dopamine synthesis capacity by PET imaging, might be more appropriate. Future studies need to address these issues. (4) Further, although copper or ceruloplasmin level in blood is affected by estrogen, the estrus cycle (Pfeiffer and Mailloux 1987), and contraceptives (Vir and Love 1981), we did not consider these factors. Our procedure is common to most of the relevant studies involving brain structural studies and hair mineral analyses. As for the estrus cycle, in this study, we used a hair copper level from a 4-cm hair sample that corresponded to hair of a few months as an independent variable of interest. The 4-cm hair sample would reflect the temporal average $\mathrm{Cu}$ metabolism over several unsynchronized estrus cycles; therefore, we believe that the estrus cycle is unlikely to be confounding variable. As for contraceptives, the additional supplemental analyses revealed that the removal of the subjects taking contraceptives did not alter the statistical strength of the significant results in the main text substantially, and we believe that the effects on the present findings are negligible (see "Supplemental Methods", "Supplemental Results" and "Supplemental Table 3"). We also conducted analyses for sex-specific effects but found no significant interaction between sex and hair copper levels on significant correlates of the hair copper levels that were presented in the main text (see "Supplemental Methods", "Supplemental Results" and "Supplemental Table 4"). (5) Finally, we were unable to determine the causal relationship or micro-level mechanisms of the observed associations between $\mathrm{Cu}$ levels, rGMV, $\mathrm{MD}$, and cognitive functions from macro-level crosssectional neuroimaging studies. However, for reference, we discussed possible mechanisms in the following discussion. In the present study, although $\mathrm{Cu}$ levels were associated with high MD and diminished cognitive functions, they were associated with high rGMVs in widespread regions in the brain. Sufficient $\mathrm{Cu}$ levels are critical to the normal development of the brain (Hunt and Idso 1995), and animal experiments have shown that even a small $\mathrm{Cu}$ deficiency disturbs the maturation of the hippocampus (Hunt and Idso 1995). A previous review of the effects of environmental factors on rGMV has suggested that extrinsic factors (e.g., nutrition and toxins) tend to globally affect rGMV to a significant extent during an earlier stage of brain development (Takeuchi and Kawashima 2016). Perhaps the contribution of high $\mathrm{Cu}$ levels to the normal development of the brain at an early stage is more dominant than other nonadaptive effects of high $\mathrm{Cu}$ levels. Partially consistent with these results, it was suggested that low $\mathrm{Cu}$ concentrations may result in incomplete development, whereas excess $\mathrm{Cu}$ concentrations may be injurious to the brain (Desai and Kaler 2008). Further, studies have suggested that during development, cortical thinning that is supposed to reflect adaptive synaptic pruning occurs, and evidence has suggested that steep cortical thinning during development is associated with increased psychometric intelligence (Shaw et al. 2006). Thus, although we are not aware of the studies indicating that $\mathrm{Cu}$ disturbs synaptic pruning, other mechanisms are possible. The present study does not identify the mechanism of regional specificity of the associations between $\mathrm{Cu}$ levels in the hair and rGMV. The associations between $\mathrm{Cu}$ levels and rGMV were detected in certain areas, including the hippocampus, but not in other regions. 
However, the absence of a significant association in other areas is not the evidence of lack and this may be attributed to the insufficient statistical power required to detect the small-effect size in epidemiological analyses of the whole brain after corrections for multiple comparisons. Alternatively, very small $\mathrm{Cu}$ deficiencies disturb the maturation of the hippocampus and dentate gyrus (Hunt and Idso 1995), and $\mathrm{Cu}$ is prominently present in the basal ganglia areas and maybe particularly important in these areas. Similarly, for some areas, $\mathrm{Cu}$ deficiency may likely lead to disturbed development in specific regions. In contrast, regarding the associations between high $\mathrm{Cu}$ levels, high MD values, and low cognitive functions, high $\mathrm{Cu}$ levels contribute to greater oxidative damage, which leads to neural damage, particularly in the substantia nigra (Segura-Aguilar et al. 2001) and increased accumulation of beta amyloid at later stages (Hashimoto 2008). Further, $\mathrm{Cu}$ triggers a proinflammatory state by modulating the production of molecules, such as IL-12, eventually injuring the tissue via this mechanism (Manto 2014). Intranigral administration of $\mathrm{Cu}$ promotes the apoptosis of dopaminergic neurons (Manto 2014). MD of the brain may reflect the amount in various types of tissues in certain regions (Johansen-Berg et al. 2012); MD is sensitive to rapid neural plasticity (Sagi et al. 2012; Takeuchi et al. 2015a). Therefore, compared with rGMV, MD may be more sensitive to recent subtle changes in the brain. Perhaps the subtle damage to neural tissues, particularly in the hippocampus and resultant functional loss, may contribute to greater MD and cognitive functions. However, these are pure speculations. However, Cu levels were not associated with cognitive abilities, traits, and states associated with dopaminergic functions such as novelty seeking and extraversion (Takeuchi et al. 2013c). These cognitions were associated with MD of the basal ganglia, thalamus, and contingent regions, but not with MD of the substantia nigra (Takeuchi et al. 2015b, 2016b) and that may partly explain lack of the significant associations. Future studies involving animals may be required to reveal the mechanisms of the present associations. Contrary to other cognitive functions, lower $\mathrm{Cu}$ levels were associated with seemingly worse cognitive function for reverse Stroop interference. However, because of the complex nature of reverse Stroop interference, it is unclear whether the results indicate that lower $\mathrm{Cu}$ levels are associated with aberrant neural function. In the present study, low $\mathrm{Cu}$ levels were associated with enhanced reverse Stroop interference, which indicates a diminished ability to resolve interference in the reverse Stroop task. However, the complex nature of this measure is known. First, the reverse Stroop effect is only observed for matching-type Stroop tasks (which we used in this study) and not for oral naming-type tasks. Further, the Stroop effect is observed for both tasks, and although patients with schizophrenia show enhanced Stroop interference and enhanced reverse Stroop interference, aging leads to enhanced Stroop interference and reduced reverse Stroop interference (Sasaki and Hakoda 1985; Sasaki et al. 1993). Working memory training using mental calculations, which increases working memory capacity, leads to increased reverse Stroop interference (Takeuchi et al. 2011a). To our knowledge, it unclear why reverse Stroop interference shows this type of antinomic character (increase of interference in schizophrenic patients, increase of interference after cognitive training involving attention, but decrease in aging). One possibility may be related to the nature of the reverse Stroop task in which one must ignore the color of the letters but must see the next stimuli outside the center of the view to solve problems as fast as possible. The widened attention capacity (or field of view) may allow one to pay attention to the color characteristics of the stimuli outside the center of the vision, but one is unable to see the exact lettering of the word when the letter is outside the center of the view. Therefore, the facilitated neurocognitive function that widens the field of view may make it difficult to ignore the color of the letters. Future studies must show whether reduced Stroop interference in subjects with high $\mathrm{Cu}$ 
levels indicates aberrant neural function. Although numerous studies have been devoted to the neurotoxicity of copper, we focused on such studies in the Introduction section. It is known that children with nutrition deficiency during prenatal development are more likely to develop obesity later in life due to epigenetic mechanisms (Tobi et al. 2014). Similarly, it is possible that copper deficiency during development may lead to neurocognitive maldevelopment and over-uptake of copper later in life and from the associations between two in the later in life. However, we believe this finding is hypothetical, and future studies need to test these ideas. In conclusion, we investigated the associations of $\mathrm{Cu}$ levels in the hair with cognitive domains, rGMV, and MD in a relatively large cohort of young subjects. Studies on animals have demonstrated the important role of $\mathrm{Cu}$ in brain development as well as the toxicity of high $\mathrm{Cu}$ levels through multiple mechanisms. Human studies have shown the (a) associations of $\mathrm{Cu}$ levels in the hair with neurophysiology (Rimland and Larson 1983; Rahman et al. 2009; Priya and Geetha 2011), (b) beneficial effects of $\mathrm{Cu}$-chelating dietary components on neurophysiology (Squitti et al. 2002), and (c) the association of high cognitive decline in the elderly subjects associated with high $\mathrm{Cu}$ intake (Hashimoto 2008). Our novel findings showed the association of high $\mathrm{Cu}$ levels in the hair with (a) aberrant cognitive functions, (b) high rGMV in widespread regions of the brain, and (c) high MD in the hippocampus and substantia nigra even in healthy young adults, suggesting complex associations of Cu levels with neurocognitive mechanisms. 


\section{References}

1. Ashburner J, Friston KJ (2000) Voxel-based morphometry-the methods. Neuroimage 11:805821CrossRefGoogle Scholar

2. Ayodele J, Bayero A (2009) Lead and zinc concentrations in hair and nail of some Kano inhabitants. African J Env Sci Tech 3:164-170Google Scholar

3. Bai X, Wang G, Wu L, Liu Y, Cui L, Shi H, Guo L (2013) Deep-gray nuclei susceptibilityweighted imaging filtered phase shift in patients with Wilson's disease. Pediatr Res 75:436442CrossRefGoogle Scholar

4. Bass DA, Hickok D, Quig D, Urek K (2001) Trace element analysis in hair: factors determining accuracy, precision, and reliability. Altern Med Rev 6:472-481 Google Scholar

5. Benjamini Y, Hochberg Y (2000) On the adaptive control of the false discovery rate in multiple testing with independent statistics. J Educ Behav Stat 25:60-83 CrossRefGoogle Scholar

6. Brewer GJ (2009) Risks of copper and iron toxicity during aging in humans. Chem Res Toxicol 23:319-326CrossRefGoogle Scholar

7. Brewer GJ (2012) Copper toxicity in Alzheimer's disease: cognitive loss from ingestion of inorganic copper. J Trace Elem Med Biol 26:89-92CrossRefGoogle Scholar

8. Castell A, Bowland J (1968) Supplemental copper for swine: Effects upon hemoglobin, serum proteins and tissue copper levels. Can J Anim Sci 48:415-424CrossRefGoogle Scholar

9. Cecil KM, Brubaker CJ, Adler CM, Dietrich KN, Altaye M, Egelhoff JC, Wessel S, Elangovan I, Hornung R, Jarvis K (2008) Decreased brain volume in adults with childhood lead exposure. PLoS Med 5:e112CrossRefGoogle Scholar

10. Chandarana H, Do RK, Mussi TC, Jensen JH, Hajdu CH, Babb JS, Taouli B (2012) The effect of liver iron deposition on hepatic apparent diffusion coefficient values in cirrhosis. Am $\mathbf{J}$ Roentgenol 199:803-808CrossRefGoogle Scholar

11. Chang CS, Choi JB, Kim HJ, Park SB (2011) Correlation between serum testosterone level and concentrations of copper and zinc in hair tissue. Biol Trace Elem Res 144:264271CrossRefGoogle Scholar

12. Chłopicka J, Zachwieja Z, Zagrodzki P, Frydrych J, Słota P, Krośniak M (1998) Lead and cadmium in the hair and blood of children from a highly industrial area in Poland. Biol Trace Elem Res 62:229-234CrossRefGoogle Scholar

13. Cloninger CR, Svrakic DM, Przybeck TR (1993) A psychobiological model of temperament and character. Arch Gen Psychiatry 50:975-990CrossRefGoogle Scholar

14. Costa PT, McCrae RR (1992) Professional manual: revised NEO personality inventory (NEOPI-R) and NEO five-factor inventory (NEO-FFI). Psychological Assessment Resources, OdessaGoogle Scholar

15. Desai V, Kaler SG (2008) Role of copper in human neurological disorders. Am J Clin Nutr 88:855S-858SCrossRefGoogle Scholar

16. Everson G, Tsai H, Wang T (1967) Copper deficiency in the guinea pig. J Nutr 93:533540CrossRefGoogle Scholar

17. Fox PL (2003) The copper-iron chronicles: the story of an intimate relationship. Biometals 16:9-40CrossRefGoogle Scholar

18. Frieden E (1980) Caeruloplasmin: a multi-functional metalloprotein of vertebrate plasma. In: Biological roles of copper, pp 93-124: Excerpta Medica AmsterdamGoogle Scholar 
19. Friedman S, Kaufman S (1965) 3, 4-dihydroxyphenylethylamine beta-hydroxylase. Physical properties, copper content, and role of copper in the catalytic acttivity. J Biol Chem 240:47634773Google Scholar

20. Gaetke LM, Chow CK (2003) Copper toxicity, oxidative stress, and antioxidant nutrients. Toxicology 189:147-163CrossRefGoogle Scholar

21. Ha J-H, Doguer C, Flores SR, Wang T, Collins JF (2018) Progressive increases in dietary iron are associated with the emergence of pathologic disturbances of copper homeostasis in growing rats. J Nutr 148:373-378CrossRefGoogle Scholar

22. Hakoda Y, Sasaki M (1990) Group version of the Stroop and reverse-Stroop test: the effects of reaction mode, order and practice. Kyoikushinrigakukenkyu (Educational Psychology Research) 38:389-394Google Scholar

23. Hashimoto M (2008) Alzheimer's disease and nutrition, especially copper, zinc and docosahexaenoic acid. Trace Nutr Res 25:8-18 Google Scholar

24. Hashimoto T, Takeuchi H, Taki Y, Sekiguchi A, Nouchi R, Kotozaki Y, Nakagawa S, Miyauchi CM, Iizuka K, Yokoyama R (2015) Neuroanatomical correlates of the sense of control: Gray and white matter volumes associated with an internal locus of control. Neuroimage 119:146151CrossRefGoogle Scholar

25. Hunt D (1980) Copper and neurological function. Biol Roles Copper 7:247-266Google Scholar

26. Hunt CD, Idso JP (1995) Moderate copper deprivation during gestation and lactation affects dentate gyrus and hippocampal maturation in immature male rats. J Nutr 125:2700-2710 Google $\underline{\text { Scholar }}$

27. Jacob RA, Klevay L, Logan G Jr (1978) Hair as a biopsy material V. Hair metal as an index of hepatic metal in rats: copper and zinc. Am J Clin Nutr 31:477-480 CrossRefGoogle Scholar

28. Johansen-Berg H, Baptista CS, Thomas AG (2012) Human structural plasticity at record speed. Neuron 73:1058-1060CrossRefGoogle Scholar

29. Jung RE, Segall JM, Jeremy Bockholt H, Flores RA, Smith SM, Chavez RS, Haier RJ (2010) Neuroanatomy of creativity. Hum Brain Mapp 31:398-409Google Scholar

30. Kedzierska E (2003) Concentrations of selected bioelements and toxic metals and their influence on health status of children and youth residing in Szczecin]. Ann Acad Med Stetin 49:131-143Google Scholar

31. Kijima N, Saito R, Takeuchi M, Yoshino A, Ono Y, Kato M, Kitamura T (1996) Cloninger-nokishitsu-to-seikaku-no-7inshimodel-oyobi-nihongoban [Cloninger's seven-factor model of temperament and character and Japanese version of Temperament and Character Inventory (TCI)]. Seishinka-shindangaku [Archives of Psychiatric. Diagn Clin Evaluat 7:379-399 Google $\underline{\text { Scholar }}$

32. Koc ER, Ilhan A, Aytürk Z, Acar B, GÜRLER M, Karapirli ALTUNTAŞA, Bodur M AS (2015) A comparison of hair and serum trace elements in patients with Alzheimer disease and healthy participants. Turkish J Med Sci 45:1034-1039 CrossRefGoogle Scholar

33. Kondo H, Morishita M, Ashida K, Osaka N (2003) Reading comprehension and working memory-structural equation modeling approach. Jpn J Psychol 73:480-487ㄷossRefGoogle $\underline{\text { Scholar }}$

34. Krejpcio Z, Olejnik D, Wójciak R, Kielczewska K, Gawęcki J (1997) Assessment of the content of calcium, magnesium, zinc and copper in hair and serum of children with hyperactivity. Polish J Environ Stud 6:89-92Google Scholar 
35. Kriegeskorte N, Simmons WK, Bellgowan PS, Baker CI (2009) Circular analysis in systems neuroscience: the dangers of double dipping. Nat Neurosci 12:535-540CrossRefGoogle Scholar

36. Lech T (2002) Lead, copper, zinc, and magnesium content in hair of children and young people with some neurological diseases. Biol Trace Elem Res 85:111-126CrossRefGoogle Scholar

37. Loef M, Walach H (2012) Copper and iron in Alzheimer's disease: a systematic review and its dietary implications. Br J Nutr 107:7-19 CrossRefGoogle Scholar

38. Maldjian JA, Laurienti PJ, Kraft RA, Burdette JH (2003) An automated method for neuroanatomic and cytoarchitectonic atlas-based interrogation of fMRI data sets. Neuroimage 19:1233-1239CrossRefGoogle Scholar

39. Maldjian JA, Laurienti PJ, Burdette JH (2004) Precentral gyrus discrepancy in electronic versions of the Talairach atlas. Neuroimage 21:450-455CrossRefGoogle Scholar

40. Manto M (2014) Abnormal copper homeostasis: mechanisms and roles in neurodegeneration. Toxics 2:327-345CrossRefGoogle Scholar

41. McNair DM, Lorr M, Droppleman LF (1992) Profile of mood states. Educational and Industrial Testing Service, San DiegoGoogle Scholar

42. Mikulewicz M, Chojnacka K, Gedrange T, Górecki H (2013) Reference values of elements in human hair: a systematic review. Environ Toxicol Pharmacol 36:1077-1086CrossRefGoogle Scholar

43. Morris MC, Evans DA, Tangney CC, Bienias JL, Schneider JA, Wilson RS, Scherr PA (2006) Dietary copper and high saturated and trans fat intakes associated with cognitive decline. Arch Neurol 63:1085-1088CrossRefGoogle Scholar

44. Nolan KR (1983) Copper toxicity syndrome. J Orthomol Psychiatry 12:270-282Google Scholar

45. Oldfield RC (1971) The assessment and analysis of handedness: the Edinburgh inventory. Neuropsychologia 9:97-113 CrossRefGoogle Scholar

46. Pal A, Siotto M, Prasad R, Squitti R (2015) Towards a unified vision of copper involvement in Alzheimer's disease: a review connecting basic, experimental, and clinical research. J

Alzheimer's Dis 44:343-354 CrossRefGoogle Scholar

47. Paris I, Dagnino-Subiabre A, Marcelain K, Bennett LB, Caviedes P, Caviedes R, Azar CO, Segura-Aguilar J (2001) Copper neurotoxicity is dependent on dopamine-mediated copper uptake and one-electron reduction of aminochrome in a rat substantia nigra neuronal cell line. J Neurochem 77:519-529 CrossRefGoogle Scholar

48. Péran P, Cherubini A, Assogna F, Piras F, Quattrocchi C, Peppe A, Celsis P, Rascol O, Démonet J-F, Stefani A (2010) Magnetic resonance imaging markers of Parkinson's disease nigrostriatal signature. Brain 133:3423-3433CrossRefGoogle Scholar

49. Pfeiffer CC, Mailloux R (1987) Excess copper as a factor in human diseases. J Orthomol Med 2:171-182Google Scholar

50. Priya MDL, Geetha A (2011) Level of trace elements (copper, zinc, magnesium and selenium) and toxic elements (lead and mercury) in the hair and nail of children with autism. Biol Trace Elem Res 142:148-158CrossRefGoogle Scholar

51. Rahman MA, Azad MAK, Hossain MI, Qusar MS, Bari W, Begum F, Huq SI, Hasnat A (2009) Zinc, manganese, calcium, copper, and cadmium level in scalp hair samples of schizophrenic patients. Biol Trace Elem Res 127:102-108CrossRefGoogle Scholar

52. Raven J (1998) Manual for Raven's progressive matrices and vocabulary scales. Oxford Psychologists Press, OxfordGoogle Scholar 
53. Razek AA, Elmongy A, Hazem M, Zakareyia S, Gabr W (2011) Idiopathic Parkinson disease effect of levodopa on apparent diffusion coefficient value of the brain. Acad Radiol 18:7073CrossRefGoogle Scholar

54. Rimland B, Larson GE (1983) Hair mineral analysis and behavior an analysis of 51 studies. J Learn Disabil 16:279-285CrossRefGoogle Scholar

55. Sagi Y, Tavor I, Hofstetter S, Tzur-Moryosef S, Blumenfeld-Katzir T, Assaf Y (2012) Learning in the fast lane: new insights into neuroplasticity. Neuron 73:1195-1203 $\underline{\text { CrossRefGoogle }}$ $\underline{\text { Scholar }}$

56. Sakai A (1970) Iron, copper, and zinc content of human hair. Nippon Eiseigaku Zasshi 25:420437CrossRefGoogle Scholar

57. Salustri C, Barbati G, Ghidoni R, Quintiliani L, Ciappina S, Binetti G, Squitti R (2010) Is cognitive function linked to serum free copper levels? A cohort study in a normal population. Clin Neurophysiol 121:502-507CrossRefGoogle Scholar

58. Sasaki M, Hakoda Y (1985) The group version of the Stroop and reverse-Stroop test (1). In: Proceedings of Japan Educational Psyhological 27th annual meeting, p 208Google Scholar

59. Sasaki M, Hakoda Y, Yamagami R (1993) Schizophrenia and reverse-Stroop interference in the group version of the Stroop and reverse-Stroop test. Jpn J Psychol 64:43-50 $\underline{\text { CrossRefGoogle }}$ $\underline{\text { Scholar }}$

60. Segura-Aguilar J, Metodiewa D, Baez S (2001) The possible role of one-electron reduction of aminochrome in the neurodegenerative process of the dopaminergic system. Neurotox Res 3:157-165CrossRefGoogle Scholar

61. Seppi K, Schocke MF, Donnemiller E, Esterhammer R, Kremser C, Scherfler C, Diem A, Jaschke W, Wenning GK, Poewe W (2004) Comparison of diffusion-weighted imaging and [123I] IBZM-SPECT for the differentiation of patients with the Parkinson variant of multiple system atrophy from those with Parkinson's disease. Mov Disord 19:14381445 CrossRefGoogle Scholar

62. Shaw P, Greenstein D, Lerch J, Clasen L, Lenroot R, Gogtay N, Evans A, Rapoport J, Giedd J (2006) Intellectual ability and cortical development in children and adolescents. Nature 440:676-679 CrossRefGoogle Scholar

63. Smith SM, Nichols TE (2009) Threshold-free cluster enhancement: addressing problems of smoothing, threshold dependence and localisation in cluster inference. NeuroImage 44:8398CrossRefGoogle Scholar

64. Society_For_Creative_Minds (1969) Manual of S-A creativity test. Tokyo shinri Corporation, TokyoGoogle Scholar

65. Squitti R, Rossini P, Cassetta E-p, Moffa F, Pasqualetti P, Cortesi M, Colloca A, Rossi L (2002) d-penicillamine reduces serum oxidative stress in Alzheimer's disease patients. Eur J Clin Invest 32:51-59 CrossRefGoogle Scholar

66. Squitti R, Bressi F, Pasqualetti P, Bonomini C, Ghidoni R, Binetti G, Cassetta E, Moffa F, Ventriglia M, Vernieri F (2009) Longitudinal prognostic value of serum "free" copper in patients with Alzheimer disease. Neurology 72:50-55CrossRefGoogle Scholar

67. Squitti R, Siotto M, Polimanti R (2014a) Low-copper diet as a preventive strategy for Alzheimer's disease. Neurobiol Aging 35:S40-S50CrossRefGoogle Scholar

68. Squitti R, Simonelli I, Ventriglia M, Siotto M, Pasqualetti P, Rembach A, Doecke J, Bush AI (2014b) Meta-analysis of serum non-ceruloplasmin copper in Alzheimer's disease. J

Alzheimer's Dis 38:809-822CrossRefGoogle Scholar 
69. Takeuchi H, Kawashima R (2016) Neural mechanisms and children's intellectual development: multiple impacts of environmental factors. Neuroscientist 22:618-631 CrossRefGoogle Scholar

70. Takeuchi H, Kawashima R (2018) Mean diffusivity in the dopaminergic system and neural differences related to dopaminergic system. Curr Neuropharmacol 16:460-474CrossRefGoogle $\underline{\text { Scholar }}$

71. Takeuchi H, Taki Y, Sassa Y, Hashizume H, Sekiguchi A, Fukushima A, Kawashima R (2010) Regional gray matter volume of dopaminergic system associate with creativity: evidence from voxel-based morphometry. Neuroimage 51:578-585CrossRefGoogle Scholar

72. Takeuchi H, Taki Y, Sassa Y, Hashizume H, Sekiguchi A, Fukushima A, Kawashima R (2011a) Working memory training using mental calculation impacts regional gray matter of the frontal and parietal regions. PLoS One 6:e23175 CrossRefGoogle Scholar

73. Takeuchi H, Taki Y, Hashizume H, Sassa Y, Nagase T, Nouchi R, Kawashima R (2011b) Failing to deactivate: the association between brain activity during a working memory task and creativity. Neuroimage 55:681-687CrossRefGoogle Scholar

74. Takeuchi H, Taki Y, Hashizume H, Sassa Y, Nagase T, Nouchi R, Kawashima R (2012) The association between resting functional connectivity and creativity. Cereb Cortex 22:29212929 CrossRefGoogle Scholar

75. Takeuchi H, Taki Y, Nouchi R, Hashizume H, Sekiguchi A, Kotozaki Y, Nakagawa S, Miyauchi CM, Sassa Y, Kawashima R (2013a) Effects of working memory-training on functional connectivity and cerebral blood flow during rest. Cortex 49:21062125CrossRefGoogle Scholar

76. Takeuchi H, Taki Y, Thyreau B, Sassa Y, Hashizume H, Sekiguchi A, Nagase T, Nouchi R, Fukushima A, Kawashima R (2013b) White matter structures associated with empathizing and systemizing in young adults. Neuroimage 77:222-236CrossRefGoogle Scholar

77. Takeuchi H, Taki Y, Sekiguchi A, Nouchi R, Kotozaki Y, Nakagawa S, Miyauchi CM, Iizuka K, Yokoyama R, Shinada T, Yamamoto Y, Hanawa S, Araki T, Hashizume H, Sassa Y, Kawashima R (2013c) Association of hair iron levels with creativity and psychological variables related to creativity. Front Hum Neurosci 7:1-9 CrossRefGoogle Scholar

78. Takeuchi H, Taki Y, Nouchi R, Hashizume H, Sekiguchi A, Kotozaki Y, Nakagawa S, Miyauchi CM, Sassa Y, Kawashima R (2015a) Working memory training impacts the mean diffusivity in the dopaminergic system. Brain Struct Funct 220:3101-3111 CrossRefGoogle $\underline{\text { Scholar }}$

79. Takeuchi H, Taki Y, Sekuguchi A, Hashizume H, Nouchi R, Sassa Y, Kotozaki Y, Miyauchi CM, Yokoyama R, Iizuka K, Nakagawa S, Nagase T, Kunitoki K, Kawashima R (2015b) Mean diffusivity of globus pallidus associated with verbal creativity measured by divergent thinking and creativity-related temperaments in young healthy adults. Hum Brain Mapp 36:18081827CrossRefGoogle Scholar

80. Takeuchi H, Taki Y, Nouchi R, Sekiguchi A, Hashizume H, Sassa Y, Kotozaki Y, Miyauchi CM, Yokoyama R, lizuka K, Seishu N, Tomomi N, Kunitoki K, Kawashima R (2015c) Degree centrality and fractional amplitude of low-frequency oscillations associated with Stroop interference. Neuroimage 119:197-209 CrossRefGoogle Scholar

81. Takeuchi H, Taki Y, Sekiguchi A, Nouchi R, Kotozaki Y, Nakagawa S, Miyauchi CM, Iizuka K, Yokoyama R, Shinada T, Yamamoto Y, Hanawa S, Araki T, Hashizume H, Sassa Y, Kawashima R (2015d) Brain structures in the sciences and humanities. Brain Struct Funct 220:3295-3305CrossRefGoogle Scholar 
82. Takeuchi H, Taki Y, Hashizume H, Asano K, Asano M, Sassa Y, Yokota S, Kotozaki Y, Nouchi R, Kawashima R (2016a) Impact of videogame play on the brain's microstructural properties: cross-sectional and longitudinal analyses. Mol Psychiatry 21:17811789 CrossRefGoogle Scholar

83. Takeuchi H, Taki Y, Sekiguchi A, Nouchi R, Kotozaki Y, Nakagawa S, Miyauchi CM, Iizuka K, Yokoyama R, Shinada T (2016b) Mean diffusivity of basal ganglia and thalamus specifically associated with motivational states among mood states. Brain Struct Funct:1-11 Google Scholar

84. Takeuchi H, Taki Y, Nouchi R, Yokoyama R, Kotozaki Y, Nakagawa S, Sekiguchi A, Iizuka K, Yamamoto Y, Hanawa S, Araki T, Miyauchi CM, Shinada T, Sakaki K, Sassa Y, Nozawa T, Ikeda S, Yokota S, Daniele M, Kawashima R (2017) Creative females have larger white matter structures: evidence from a large sample study. Hum Brain Mapp 38:414-430 $\underline{\text { CrossRefGoogle }}$ $\underline{\text { Scholar }}$

85. Taki Y, Hashizume H, Sassa Y, Takeuchi H, Wu K, Asano M, Asano K, Fukuda H, Kawashima R (2011) Correlation between gray matter density-adjusted brain perfusion and age using brain MR images of 202 healthy children. Hum Brain Mapp 32:1973-1985CrossRefGoogle Scholar

86. Tanaka K, Okamoto K, Tanaka H (2003) Manual of new tanaka B type intelligence test. Kaneko Syobo, TokyoGoogle Scholar

87. Tobi EW, Goeman JJ, Monajemi R, Gu H, Putter H, Zhang Y, Slieker RC, Stok AP, Thijssen PE, Müller F (2014) DNA methylation signatures link prenatal famine exposure to growth and metabolism. Nat Commun 5:5592CrossRefGoogle Scholar

88. Turnlund JR, Jacob RA, Keen CL, Strain J, Kelley DS, Domek JM, Keyes WR, Ensunsa JL, Lykkesfeldt J, Coulter J (2004) Long-term high copper intake: effects on indexes of copper status, antioxidant status, and immune function in young men. Am J Clin Nutr 79:10371044CrossRefGoogle Scholar

89. Tzourio-Mazoyer N, Landeau B, Papathanassiou D, Crivello F, Etard O, Delcroix N, Mazoyer B, Joliot M (2002) Automated anatomical labeling of activations in SPM using a macroscopic anatomical parcellation of the MNI MRI single-subject brain. Neuroimage 15:273289CrossRefGoogle Scholar

90. Vir SC, Love A (1981) Zinc and copper nutriture of women taking oral contraceptive agents. Am J Clin Nutr 34:1479-1483CrossRefGoogle Scholar

91. Wilson L (2003) Nutritional balancing and hair tissue mineral analysis. Explore-Mount Vernon 12:42-53 Google Scholar

92. Yokoyama K (2005) POMS Shortened Version (in Japanese). Kanekoshobo, Tokyo $\underline{\text { Google }}$ $\underline{\text { Scholar }}$

93. Zecca L, Zucca F, Toscani M, Adorni F, Giaveri G, Rizzio E, Gallorini M (2005) Iron, copper and their proteins in substantia nigra of human brain during aging. J Radioanal Nuclear Chem 263:733-737 $\underline{\text { CrossRefGoogle Scholar }}$ 
Table 1

The demographics of study participants

\begin{tabular}{|l|l|l|l|l|}
\hline \multirow{2}{*}{ Measure } & \multicolumn{2}{|c|}{ Male $(\boldsymbol{N}=\mathbf{5 6 3})$} & \multicolumn{2}{l|}{ Female $(\boldsymbol{N}=\mathbf{3 6 1})$} \\
\cline { 2 - 5 } & Mean & SD & Mean & SD \\
\hline Age & 20.83 & 1.93 & 20.54 & 1.64 \\
\hline RAPM & 28.77 & 3.89 & 28.00 & 3.87 \\
\hline Log-Copper & 4.31 & 0.2 & 4.37 & 0.22 \\
\hline Raw hair copper level $(\mu \mathrm{g} / \mathrm{g})$ & 24.01 & 31.28 & 27.34 & 18.72 \\
\hline
\end{tabular}


Table 2

Statistical results (beta value, $t$ value, uncorrected $p$ values, $p$ value corrected for FDR) for the multiple regression analyses performed using psychological variables and the copper level after correcting for confounding variables

\begin{tabular}{|c|c|c|c|c|c|}
\hline \multirow[t]{2}{*}{ Dependent variables } & \multirow[t]{2}{*}{$N$} & \multirow[t]{2}{*}{$\boldsymbol{\beta}$} & \multirow[t]{2}{*}{$t$} & \multicolumn{2}{|c|}{ Cu level } \\
\hline & & & & $\begin{array}{c}p \\
\text { (uncorrected) }\end{array}$ & $p$ (FDR) \\
\hline RAPM $^{\mathrm{a}}$ & 919 & -0.044 & -1.326 & 0.185 & 0.107 \\
\hline $\begin{array}{l}\text { Total intelligence } \\
\text { score of } \mathrm{TBIT}^{\mathrm{b}}\end{array}$ & 847 & -0.070 & -2.060 & 0.040 & 0.040 \\
\hline $\begin{array}{l}\text { Perception score of } \\
\text { TBIT }\end{array}$ & 847 & -0.066 & -1.884 & 0.060 & 0.053 \\
\hline $\begin{array}{l}\text { Spatial relation factor } \\
\text { of TBIT }\end{array}$ & 853 & -0.036 & -1.068 & 0.286 & 0.152 \\
\hline $\begin{array}{l}\text { Reasoning factor of } \\
\text { TBIT }\end{array}$ & 853 & -0.069 & -2.085 & 0.037 & 0.040 \\
\hline Simple arithmetic & 664 & -0.030 & -0.775 & 0.439 & 0.219 \\
\hline Complex arithmetic & 664 & -0.108 & -2.767 & 0.006 & 0.035 \\
\hline $\begin{array}{l}\text { Reverse stroop } \\
\text { interference }\end{array}$ & 922 & -0.072 & -2.164 & 0.031 & 0.040 \\
\hline Stroop interference & 921 & 0.044 & 1.318 & 0.188 & 0.107 \\
\hline $\begin{array}{l}\text { Reading } \\
\text { comprehension }\end{array}$ & 840 & -0.074 & -2.114 & 0.035 & 0.040 \\
\hline S-A creativity test & 924 & -0.049 & -1.483 & 0.138 & 0.092 \\
\hline Digit span & 919 & -0.009 & -0.268 & 0.789 & 0.332 \\
\hline POMS ${ }^{\mathrm{c}}$-Vigor & 913 & -0.057 & -1.718 & 0.086 & 0.069 \\
\hline Extraversion & 923 & -0.023 & -0.684 & 0.494 & 0.232 \\
\hline Novelty seeking & 922 & 0.053 & 1.591 & 0.112 & 0.081 \\
\hline
\end{tabular}

The table presents the beta values, $t$ values, uncorrected $p$ values, and $p$ values corrected for $\mathrm{FDR}^{\mathrm{a}}$ for the multiple regression analyses performed using psychological variables and $\mathrm{Cu}$ levels after correcting for confounding variables 
$F D R$ false discovery rate

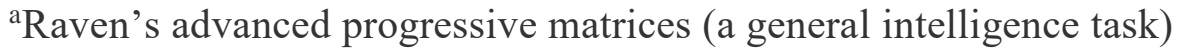

${ }^{\mathrm{b}}$ Tanaka B-type intelligence test

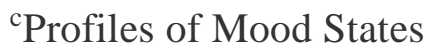

\section{Table 3}

Brain regions that exhibited significant positive correlations between the logarithms of $\mathrm{Cu}$ levels in the hair and rGMVs

\begin{tabular}{|c|c|c|c|c|c|c|}
\hline $\begin{array}{l}\text { Included gray matter } \\
\text { areas }{ }^{\text {a }} \text { number of } \\
\text { significant voxels in the } \\
\text { left and right sides of } \\
\text { each anatomical area) }\end{array}$ & $x$ & $y$ & $z$ & $\begin{array}{l}\text { TFCE } \\
\text { value }\end{array}$ & $\begin{array}{l}\text { Corrected } p \text { value } \\
\text { (FWE) }\end{array}$ & $\begin{array}{c}\text { Cluster } \\
\text { size } \\
\text { (voxel) }\end{array}$ \\
\hline $\begin{array}{l}\text { Amygdala (L:462, } \\
\text { R:529)/Angular gyrus } \\
\text { (L:1042, } \\
\text { R:3010)/Calcarine cortex } \\
\text { (L:33, R:197)/Caudate } \\
\text { (R:69)/Middle cingulum } \\
\text { (L:1240, } \\
\text { R:1699)/Posterior } \\
\text { cingulum (L:582, } \\
\text { R:363)/Cuneus (L:228, } \\
\text { R:335)/Inferior frontal } \\
\text { operculum (L:3)/Inferior } \\
\text { frontal orbital area } \\
\text { (L:746, R:1279)/Inferior } \\
\text { frontal triangular } \\
\text { (L:318)/Middle frontal } \\
\text { orbital area (L:15, } \\
\text { R:93)/Superior frontal } \\
\text { orbital area (L:215, } \\
\text { R:280)/Superior frontal } \\
\text { other areas (L:51, } \\
\text { R:5)/Fusiform gyrus } \\
\text { (L:6, R:85)/Heschl gyrus } \\
\text { (L:216)/Hippocampus } \\
\text { (L:1007, R:786)/Insula } \\
\text { (L:2023, }\end{array}$ & 27 & $\begin{array}{l}- \\
46.5\end{array}$ & 64.5 & 3177.48 & $<0.001$ & 79,611 \\
\hline
\end{tabular}




\begin{tabular}{|c|c|c|c|c|c|c|}
\hline $\begin{array}{l}\text { Included gray matter } \\
\text { areas }^{\text {a }} \text { number of } \\
\text { significant voxels in the } \\
\text { left and right sides of } \\
\text { each anatomical area) }\end{array}$ & $x$ & $y$ & $z$ & $\begin{array}{l}\text { TFCE } \\
\text { value }\end{array}$ & $\begin{array}{l}\text { Corrected } p \text { value } \\
\text { (FWE) }\end{array}$ & $\begin{array}{c}\text { Cluster } \\
\text { size } \\
\text { (voxel) }\end{array}$ \\
\hline $\begin{array}{l}\text { R:1500)/Lingual gyrus } \\
\text { (R:1186)/Middle } \\
\text { occipital lobe (L:2314, } \\
\text { R:1321)/Superior } \\
\text { occipital lobe (L:89, } \\
\text { R:102)/Pallidum (L:94, } \\
\text { R:1)/Paracentral lobule } \\
\text { (L:1049, } \\
\text { R:818)/Parahippocampal } \\
\text { gyrus (L:482, } \\
\text { R:798)/Inferior parietal } \\
\text { lobule (L:1799, } \\
\text { R:2117)/Superior parietal } \\
\text { lobule (L:2302, } \\
\text { R:1976)/Postcentral } \\
\text { gyrus (L:1068, } \\
\text { R:3026)/Precentral gyrus } \\
\text { (L:639, } \\
\text { R:285)/Precuneus } \\
\text { (L:4903, } \\
\text { R:3891)/Putamen (L:920, } \\
\text { R:488)/Rectus gyrus } \\
\text { (L:252, R:70)/Rolandic } \\
\text { operculum (L:545, } \\
\text { R:170)/Supplemental } \\
\text { motor area (L:978, } \\
\text { R:1289)/Supramarginal } \\
\text { gyrus (L:1511, } \\
\text { R:2721)/Inferior } \\
\text { temporal gyrus } \\
\text { (R:841)/Middle temporal } \\
\text { gyrus (L:269, } \\
\text { R:2091)/Temporal pole } \\
\text { (L:1588, } \\
\text { R:2197)/Superior } \\
\text { temporal gyrus (L:1302, } \\
\text { R:923)/Cerebellum } \\
\text { (R:2)/ }\end{array}$ & & & & & & \\
\hline
\end{tabular}




\begin{tabular}{|l|c|c|c|c|c|c|}
\hline $\begin{array}{l}\text { Included gray matter } \\
\text { areas(number of } \\
\text { significant voxels in the } \\
\text { left and right sides of } \\
\text { each anatomical area) }\end{array}$ & $\boldsymbol{x}$ & $\boldsymbol{y}$ & $\boldsymbol{z}$ & $\begin{array}{l}\text { TFCE } \\
\text { value }\end{array}$ & $\begin{array}{c}\text { Corrected } \boldsymbol{p} \text { value } \\
\text { (FWE) }\end{array}$ & $\begin{array}{c}\text { Cluster } \\
\text { size } \\
\text { (voxel) }\end{array}$ \\
\hline None & -18 & 27 & -7.5 & 1365.34 & 0.048 & 22 \\
\hline
\end{tabular}

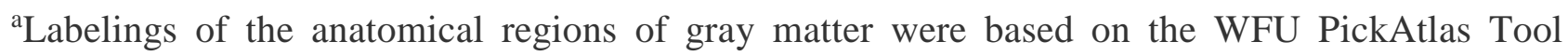
(http://www.fmri.wfubmc.edu/cms/software\#PickAtlas/) (Maldjian et al. 2003, 2004) and on the PickAtlas automated anatomical labeling atlas option (Tzourio-Mazoyer et al. 2002). Temporal pole areas included all subregions in the areas of this atlas

\section{Table 4}

Statistical results (beta value, $t$ value, uncorrected $p$ values, $p$ value corrected for FDR) for the multiple regression analyses performed using mean diffusivity (MD) or each region of interest and the copper level after correcting for confounding variables

\begin{tabular}{|c|c|c|c|c|c|}
\hline \multirow[t]{2}{*}{ Dependent variables } & \multirow[t]{2}{*}{$N$} & \multirow[t]{2}{*}{$\boldsymbol{\beta}$} & \multirow[t]{2}{*}{$t$} & \multicolumn{2}{|l|}{ Copper level } \\
\hline & & & & $p$ (uncorrected) & $p($ FDR $)$ \\
\hline $\begin{array}{l}\text { MD of the right substantia } \\
\text { nigra }\end{array}$ & 924 & 0.082 & 2.624 & 0.009 & 0.035 \\
\hline MD of the left substantia nigra & 924 & -0.010 & -0.303 & 0.762 & 0.332 \\
\hline MD of the right hippocampus & 924 & 0.069 & 2.127 & 0.034 & 0.040 \\
\hline MD of the left hippocampus & 924 & 0.068 & 2.131 & 0.033 & 0.040 \\
\hline
\end{tabular}

The table presents beta values, $t$ values, uncorrected $p$ values, and $p$ values corrected for FDR for multiple regression analyses performed using the mean diffusivity (MD) or each region of interest and $\mathrm{Cu}$ levels after correcting for confounding variables

$F D R$ false discovery rate 


\section{Fig. 1}

Scatter plots of significant associations between copper $(\mathrm{Cu})$ levels in the hair (logarithms of copper levels in the hair) and cognitive functions. The scatter plots include associations of the $\mathrm{Cu}$ level in the hair with the total intelligence score of TBIT, reasoning factor of TBIT, complex arithmetic, reverse Stroop interference, and a reading comprehension task. The statistical values were those of the multiple regression analyses after correcting for confounding variables
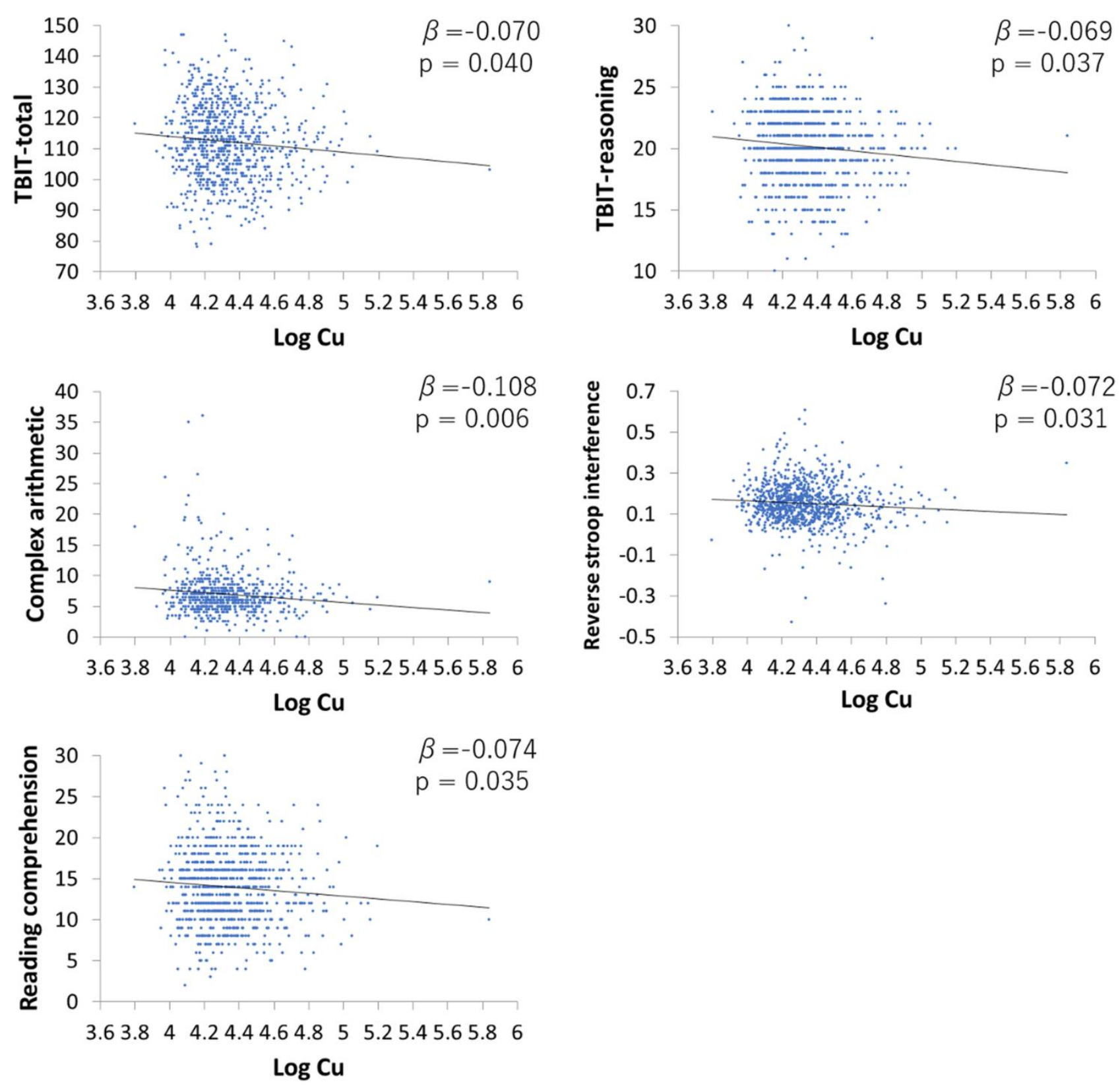


\section{Fig. 2}

The positive rGMV correlates with $\mathrm{Cu}$ levels in the hair. The results were obtained using a threshold of threshold-free cluster enhancement (TFCE) of $P<0.05$ based on 5,000 permutations. The results were corrected at the whole-brain level. Upper panel: regions with significant correlations are projected on a rendered SPM8 image. Significant positive correlations with rGMV were observed in extensive cortical regions, particularly in the parietal lobes and in regions of perisylvian areas. Lower panels: regions with significant correlations between rGMV and $\mathrm{Cu}$ levels in the hair are overlaid on a "single subject" $\mathrm{T} 1$ image from SPM8. Significant positive correlations between rGMV and $\mathrm{Cu}$ levels in the hair were observed in extensive regions throughout the brain, particularly in the lateral and medial parietal lobes, perisylvian areas, medial temporal areas, and the insula. The color bar represents the TFCE score. It reflects both voxel's height and the sum of the spatially contiguous voxels supporting it; therefore, it reflects both the strength and extent of effects
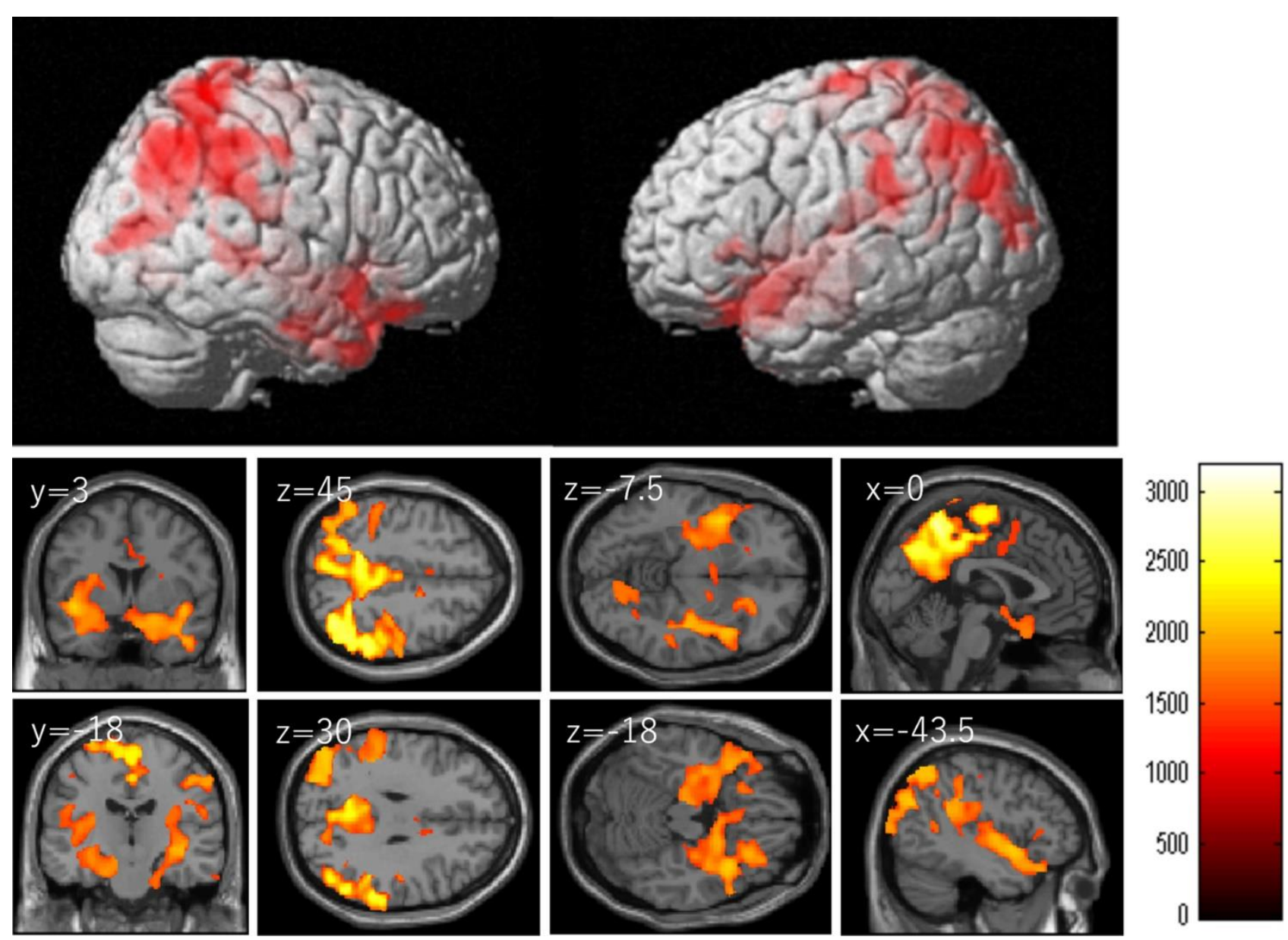

0 


\section{Fig. 3}

Scatter plots of the associations between copper levels in the hair (logarithms of Cu levels in the hair) and the MD of the bilateral substantia nigra and bilateral hippocampus. Significant associations were found in the right substantia nigra and bilateral hippocampus, but not in the left substantia nigra. The statistical values are those of multiple regression analyses after correcting for confounding variables
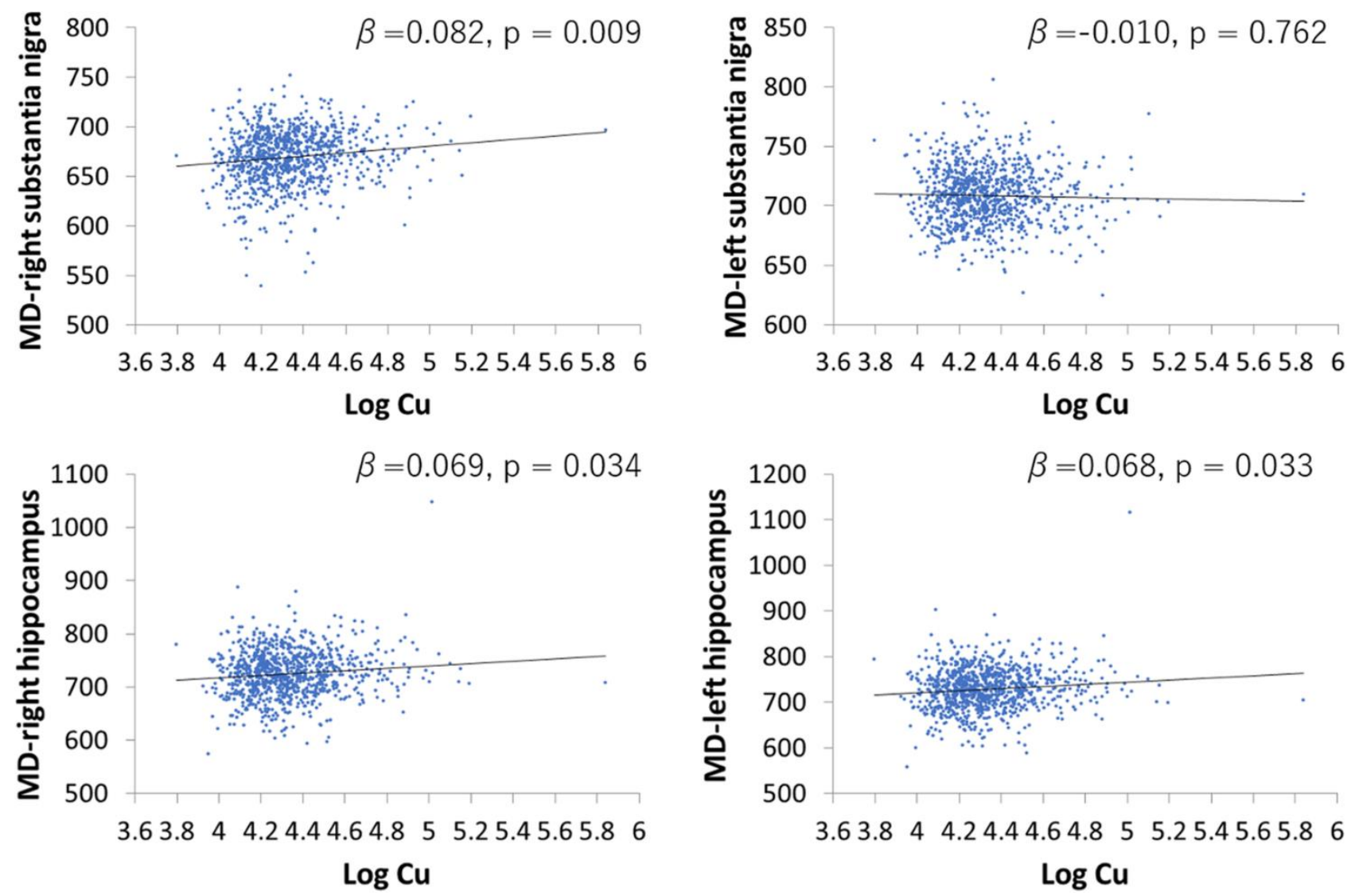


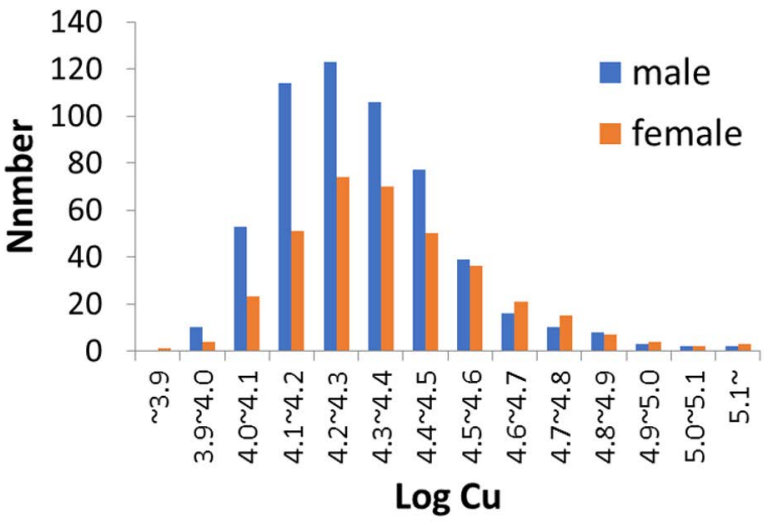




\section{Supplemental online material}

\section{Supplemental Methods}

Subjects. The present study, which is a part of an ongoing project to investigate the association between brain imaging, cognitive function, and aging, included 924 healthy, right-handed individuals (563 men and 361 women) for whom relevant measures were collected. The mean ( \pm standard deviation, SD) age of the subjects was $20.7 \pm 1.8$ years (age range, 18-27 years). Some of the subjects who took part in this study also became subjects of our intervention studies (psychological data and imaging data recorded before the intervention were used in this study)(Takeuchi et al., 2014). Psychological tests and MRI scans not described in this study were performed together with those described in this study. Written informed consent was obtained from each subject. For nonadult subjects, written informed consent was obtained from their parents (guardians). This study was approved by the Ethics Committee of Tohoku University. Subjects were instructed to get sufficient sleep, maintain their conditions, eat sufficient breakfast, and to consume their normal amounts of caffeinated foods and drinks in the day of cognitive tests and MRI scans. In addition, subjects were instructed to avoid alcohol the night before the assessment.

These descriptions in this subsection were mostly reproduced from another study of ours from the same project using the exactly same methods regarding these issues (Takeuchi et al., 2015).

\section{Hair acquisition and hair mineral analysis}

Scalp hair samples (approximately 4-cm length, 0.1-g weight) were collected from each subject, with the hair cut as close to the scalp as possible. The hair samples were sent to 
La Belle Vie research laboratory and analyzed by established methods (Munakata et al., 2006; Yasuda et al., 2011; Yasuda et al., 2012; Yasuda et al., 2005a; Yasuda et al., 2008; Yasuda et al., 2009), as described below.

Hair sample of $75 \mathrm{mg}$ was weighed into $50 \mathrm{ml}$ plastic tube, and washed twice with acetone and then with $0.01 \%$ Triton solution, in accordance with the procedures recommended by the Hair Analysis Standardization Board (Cranton et al., 1982). The washed hair sample was mixed with $10 \mathrm{ml}$ 6.25\% tetramethylammonium hydroxide (TMAH, Tama Chemical) and $50 \mu 10.1 \%$ gold solution (SPEX Certi Prep.), and then dissolved at $75^{\circ} \mathrm{C}$ with shaking for $2 \mathrm{~h}$. After cooling of the solution to room temperature, internal standard (Sc, Ga, and $\mathrm{In}$ ) solution was added and, adjusting its volume gravimetrically, the obtained solution was used for mineral analysis. The mineral concentrations were measured with inductively coupled plasma mass spectrometry (ICPMS; Agilent-7500ce) by the internal standard method (Yasuda et al., 2005a; Yasuda et al., 2005b; Yasuda et al., 2007), and are expressed as ng/g hair (ppb). For quality control of the mineral analysis, the human hair certified reference material supplied from the National Institute for Environmental Studies of Japan (NIES CRM no. 13) (Yoshinaga et al., 1997) was used.

The description in this subsection is reproduced from our previous study that used the same method (Takeuchi et al., 2013c).

We also obtained information regarding the last time when subjects underwent hair coloring, perming, and bleaching from most subjects. The possible answers could be divided as follows: (a) within 1 month, (b) within 1-2 months, (c) within 2-3 months, and (d) within 3-6 months, and (e) not accomplished within 6 months. Scalp hair samples (approximately 4-cm long) were collected from each subject, with the hair 
cut as close to the scalp as possible. Therefore, based on hair growth, the answers were coded as follows: $(a)=3,(b)=2,(c)=1,(d)=0.5$, and $(e)=0$. We investigated the associations of these values and copper $(\mathrm{Cu})$ levels in the hair after correcting for sex. Although only the history of hair coloring showed a significant correlation, the effect size was weak [standardized beta coefficient $(\beta)<0.1$ ] as a covariate compared with that of magnesium, calcium, selenium, and others $[(\beta)$ approximately 0.4$]$, and therefore, its effect was not considered. The additional analyses, including that of the history of coloring as a covariate, did not substantially affect the strength of significant associations in the present study.

Details of diffusion image acquisition. There are acquisitions for phase correction and for signal stabilization and these are not used as reconstructed images. MD and FA maps were calculated from the collected images using a commercially available diffusion tensor analysis package on the MR consol. This practice has been used in many of our previous studies (Takeuchi et al., 2010a, 2011; Takeuchi et al., 2010b; Takeuchi et al., 2013a; Takeuchi et al., 2013b). Furthermore, the results of analyses using these image-generated results were congruent with those of previous studies in which other methods were used (Barnea-Goraly et al., 2005; Taki et al., 2013), suggesting the validity of this method. These procedures involved correction for motion and distortion caused by eddy currents. Calculations were performed according to a previously proposed method (Le Bihan et al., 2001). Descriptions in this subsection were mostly reproduced from a previous study using similar methods (Takeuchi et al., 2016a).

Pre-processing of structural data. Preprocessing of the structural data was performed 
using Statistical Parametric Mapping software (SPM12; Wellcome Department of Cognitive Neurology, London, UK) implemented in Matlab (Mathworks Inc., Natick, MA, USA). Using the new segmentation algorithm implemented in SPM12, T1weighted structural images of each individual were segmented into 6 tissues. In this new segmentation process, default parameters were used, except that the Thorough Clean option was used to eliminate any odd voxel, affine regularization was performed with the International Consortium for Brain Mapping template for East Asian brains, and the sampling distance was set at $1 \mathrm{~mm}$. We then proceeded to the diffeomorphic anatomical registration through exponentiated lie algebra (DARTEL) registration process implemented in SPM12. We used DARTEL import images of the 2 tissue probability maps from the abovementioned new segmentation process. First, the template for the DARTEL procedures was created using imaging data from 800 participants (400 males and 400 females). Next, using this existing template, the DARTEL procedures were performed for all of the subjects in the present study. In these procedures, default parameter settings were used. The resulting images were spatially normalized to the Montreal Neurological Institute (MNI) space to give images with $1.5 \times 1.5 \times 1.5 \mathrm{~mm}^{3}$ voxels. In addition, we performed a volume change correction (modulation) by modulating each voxel with the Jacobian determinants derived from spatial normalization, which allowed us to determine regional differences in the absolute amount of brain tissue (Ashburner and Friston, 2000). Subsequently, all images were smoothed by convolving them with an isotropic Gaussian kernel of $8 \mathrm{~mm}$ full width at half maximum (FWHM). The description in this paragraph was mainly reproduced from our previous study that used the same method (Takeuchi et al., 2017).

Preprocessing and analysis of diffusion weighted imaging data were performed 
using SPM8 implemented in Matlab. Most of the following descriptions were reproduced from our previous study using the similar methods (Takeuchi et al., 2016a). First, the skull in the mean $b=0$ image of each participant was stripped as described previously (Takeuchi et al., 2010a); using the resulting image, diffusion images were linearly aligned to the skull-stripped $b=0$ image template created previously (Takeuchi et al., 2010a) to assist with the following procedures. Subsequently, using a previously validated two-step new segmentation algorithm of diffusion images and the previously validated diffeomorphic anatomical registration through exponentiated lie algebra (DARTEL)-based registration process that utilized the information of the FA signal distribution within the white matter tissue (for details, see Takeuchi et al., 2013b), all images, including gray matter segments [regional gray matter density (rGMD) map], white matter segments [regional white matter density (rWMD) map], and cerebrospinal fluid (CSF) segments [regional CSF density (rCSFD) map] of diffusion images, were normalized. The voxel size of these normalized images was $1.5 \times 1.5 \times 1.5 \mathrm{~mm}^{3}$. In these processes, we used the template for the DARTEL process that we created in our previous study from subjects that participated in the same project (for details, see Takeuchi et al., 2013b). Next, we created average images of normalized rGMD and rWMD images of all subjects whose diffusion imaging data were obtained in the preexperiment. Subsequently, for the analyses of MD images from the normalized images of the (a) MD, (b) rGMD, and (c) rCSFD maps, we created images where areas that were not strongly likely to be gray or white matter in our averaged normalized rGMD and rWMD images (defined by "gray matter tissue probability + white matter tissue probability $<0.99$ ") were removed (to exclude the strong effects of CSF on MD throughout analyses). These images were then smoothed $(8 \mathrm{~mm}$ full-width half- 
maximum) and carried through to the second-level analyses of MD. We did not use T1 weighted structural images for normalization and calculation of GMD and WMD maps for correction. This is because T1 weighted structural images and EPI images have apparent differences due to the distortion caused by 3T MRI and simply it is apparently not suited for the accurate and precise segmentation and normalization images of MD maps.

Construction of regions of interest (ROI) for MD. The ROI masks for the bilateral substantia nigra and bilateral hippocampus were constructed using the Brodmann area option in the WFU PickAtlas Tool (http://www.fmri.wfubmc.edu/cms/software\#PickAtlas) (Maldjian et al., 2004; Maldjian et al., 2003) and the aal option in the WFU PickAtlas Tool, respectively. Note that the aal option is widely used but does not include the anatomical mask for the substantia nigra. Subsequently, the mean MD values of these images were extracted from the aforementioned normalized images. Here, we limited the areas to extract these values from within the areas that showed "gray matter tissue probability + white matter tissue probability $>0.999$ " in the custom template mentioned above. The descriptions in this subsection were reproduced in part from our previous study that used similar methods (Takeuchi et al., 2016b).

Additional non-whole brain multiple regression analyses correcting for effects of hair iron level

To evaluate the potential effects of hair iron level on the significant associations with hair copper level described in the main text, we performed additional non-whole 
brain multiple regression analyses including hair iron level as an additional covariate in addition to all other covariates that were described in the main text. Hair iron level was assessed in the same way as hair copper level, and the logarithm of hair iron level was used in the analysis. We compared these results with those of multiple regression analyses in the main text that did not include hair iron level as a covariate. Here independent variables were the 15 psychological variables, MD of the left and right hippocampus, MD of the left and right substantia nigra, and total gray matter volume. Total gray matter volume was used instead of mean rGMV value of the significant cluster from whole brain multiple regression analyses to avoid effects of double-dipping procedures for the whole brain analyses (Kriegeskorte et al., 2009) on evaluation and also because widespread associations between rGMV and hair copper level were observed and hair copper level positively correlated with total gray matter volume.

Additional non-whole brain multiple regression analyses excluding subjects who reported taking contraceptives

To evaluate the potential effects of contraceptives, we performed additional nonwhole brain multiple regression analyses excluding subjects who reported taking contraceptives. The rest of the procedures were the same as those for the evaluation of the impacts of hair iron levels on the results of the study as described above. We compared these results with those of multiple regression analyses of the main text (analyses including samples who reported taking contraceptives).

Additional non-whole brain analyses of covariance for effects of the interaction between sex and hair copper levels on significant correlates of hair copper levels. 
To investigate whether psychological and anatomical correlates of hair copper levels are driven by males or females alone (in other words, to test whether the associations with hair copper level and its correlates differ between males and females), we performed additional analyses using ANCOVA with PASW Statistics 22. The dependent variables were the same as those used in analyses that corrected for effects of hair iron levels, as described above. In these analyses, the subjects were divided into two groups based on sex. We added the interaction between the hair copper level and this group factor as a covariate in the models for each analysis in addition to all other covariates that were used in abovementioned analyses for effects of contraceptives. We did not have an a priori hypothesis for these analyses. Thus, we simply applied the pvalues of interaction effects from the ANCOVAs through F-tests.

\section{Supplemental Results}

Additional non-whole brain multiple regression analyses correcting for the effects of hair iron level

We compared the results of the multiple regression analyses including the covariates listed in the main text with the results of the multiple regression analyses that additionally added hair iron level as a covariate. Among the significant results in the main text, all the p-values of the associations between hair copper level and dependent values except that of reasoning factor of TBIT were lower in the former analyses. Therefore, the significance of results of the associations of hair copper levels were mostly unaffected by the consideration of effects of hair iron level. 
Additional non-whole brain multiple regression analyses excluding subjects who reported taking contraceptives

We compared the results of multiple regression analyses using the same sample as in main text with the results of the multiple regression analyses excluding subjects who reported using contraceptives. Among the entire sample of 925 subjects, 13 reported using contraceptives. In the results, some of the statistical values of the significant results in the main text got slightly stronger after excluding subjects who reported using contraceptives, whereas others got slightly weaker, but all remained significant even without subjects who were taking contraceptives. Therefore, we concluded that the effects of taking contraceptives were negligible to the significant results in this study. We have attached the statistical values in (Supplemental table 3).

Additional non-whole brain analyses of covariance for effects of the interaction between sex and hair copper levels on significant correlates of hair copper levels.

We found no significant effects of the interaction between sex and hair copper levels on any of the variables investigated (Supplemental Table 4). Therefore, there is no statistical evidence that the results presented in the main text are driven by the effects of males or females alone. 


\section{Supplemental Table 1.}

Statistical results (beta value, $t$-value, uncorrected $p$-values) for the multiple regression analyses of the associations between hair copper level and dependent variables with or without covariates of hair iron level.

\begin{tabular}{|c|c|c|c|c|c|c|}
\hline \multirow[b]{5}{*}{ Dependent variables } & \multicolumn{3}{|c|}{ Other Covariates: sex age self- } & \multicolumn{3}{|c|}{ Other Covariates: sex, age, self- } \\
\hline & \multicolumn{3}{|c|}{ reported height, self-reported } & \multicolumn{3}{|c|}{ reported height, self-reported } \\
\hline & weight a & body ma & (BMI) & weight & BMI, $\mathrm{h}$ & level \\
\hline & $\beta$ & $t$ & 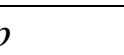 & $\beta$ & $t$ & p \\
\hline & & & rected) & & & rected) \\
\hline RAPM $^{\mathrm{a}}$ & -0.044 & -1.326 & 0.185 & -0.039 & -1.157 & 0.248 \\
\hline Total intelligence score of TBIT $^{b}$ & -0.070 & -2.060 & 0.040 & -0.074 & -2.127 & 0.034 \\
\hline Perception score of TBIT & -0.066 & -1.884 & 0.060 & -0.070 & -1.978 & 0.048 \\
\hline Spatial relation factor of TBIT & -0.036 & -1.068 & 0.286 & -0.041 & -1.199 & 0.231 \\
\hline Reasoning factor of TBIT & -0.069 & -2.085 & 0.037 & -0.065 & -1.933 & 0.054 \\
\hline Simple arithmetic & -0.030 & -0.775 & 0.439 & -0.030 & -0.756 & 0.450 \\
\hline Complex arithmetic & -0.108 & -2.767 & 0.006 & -0.114 & -2.893 & 0.004 \\
\hline
\end{tabular}




$\begin{array}{lcccccr}\text { Reverse Stroop interference } & -0.072 & -2.164 & 0.031 & -0.073 & -2.181 & 0.029 \\ \text { Stroop interference } & 0.044 & 1.318 & 0.188 & 0.049 & 1.443 & 0.149 \\ \text { Reading comprehension } & -0.074 & -2.114 & 0.035 & -0.086 & -2.439 & 0.015 \\ \text { S-A creativity test } & -0.049 & -1.483 & 0.138 & -0.060 & -1.789 & 0.074 \\ \text { Digit span } & -0.009 & -0.268 & & -0.008 & -.229 & 0.819 \\ \text { POMSc-Vigor } & -0.057 & -1.718 & 0.086 & -0.060 & -1.782 & 0.075 \\ \text { Extraversion } & -0.023 & -0.684 & 0.494 & -0.029 & -0.872 & 0.383 \\ \text { Novelty seeking } & 0.053 & 1.591 & 0.112 & 0.041 & 1.240 & 0.215 \\ \text { Total gray matter volume* } & 0.054 & 2.697 & 0.007 & 0.055 & 2.721 & 0.007 \\ \text { MD of the right substantia nigra } & 0.082 & 2.624 & 0.009 & 0.088 & 2.764 & 0.006 \\ \text { MD of the left substantia nigra } & -0.010 & -0.303 & 0.762 & -0.019 & -0.575 & 0.565 \\ \text { MD of the right hippocampus } & 0.069 & 2.127 & 0.034 & 0.073 & 2.229 & 0.026 \\ \text { MD of the left hippocampus } & 0.068 & 2.131 & 0.033 & 0.072 & 2.205 & 0.028\end{array}$

${ }^{\mathrm{a}}$ Raven's advanced progressive matrices (a general intelligence task). ${ }^{\mathrm{b}}$ Tanaka B-type intelligence test, ${ }^{\mathrm{c}}$ Profiles of Mood States. 
*In the analyses of total gray matter volume, total intracranial volume was added as a covariate in addition to other covariates. To avoid double dipping procedure (Kriegeskorte et al., 2009), in the analyses for gray matter volume, total gray matter volume was used instead of regional gray matter volume of the cluster showing significant psychological and neuroimaging correlates of hair copper level. 
Supplemental Table 2. Standardized partial regression coefficients ( $\beta$ values) and p-values for the multiple regression analyses that investigated the associations between hair copper levels and the significant psychological and neuroimaging correlates of hair copper level in this study.

\begin{tabular}{|c|c|c|c|c|c|c|c|c|c|c|}
\hline & 1 & 2 & 3 & 4 & 5 & 6 & $7^{1}$ & 8 & 9 & 10 \\
\hline $1 \mathrm{Cu}$ level & - & & $*$ & $* *$ & $* * *$ & & & & & \\
\hline 2 Total & -0.070 & - & & & & & & & & \\
\hline intelligence score & $0.040 *$ & & & & & & & & & \\
\hline of TBIT & & & & & & & & & & \\
\hline 3 Reasoning & -0.069 & 0.632 & - & & & & & & & \\
\hline factor of TBIT & $0.037^{*}$ & $1.43 \times 10^{-89 * * *}$ & & & & & & & & \\
\hline 4 Complex & -0.108 & 0.229 & 0.221 & - & & & & & & \\
\hline arithmetic & $0.006^{* *}$ & $1.65 \times 10^{-9 * * *}$ & $1.09 \times 10^{-9 * * *}$ & & & & & & & \\
\hline 5 Reverse Stroop & -0.072 & -0.055 & -0.029 & -0.016 & - & & & & & \\
\hline interference & $0.031 *$ & 0.107 & 0.381 & 0.675 & & & & & & \\
\hline 6 Reading & -0.074 & 0.231 & 0.094, & -0.020 & -0.025 & - & & & & \\
\hline
\end{tabular}




\begin{tabular}{|c|c|c|c|c|c|c|c|c|c|}
\hline comprehension & $0.035 *$ & $5.32 \times 10^{-11 * * *}$ & $0.006 * *$ & 0.635 & 0.472 & & & & \\
\hline 7 Total gray & 0.054 & 0.085 & 0.081 & -0.141 & -0.016 & 0.033 & - & & \\
\hline matter volume $^{1}$ & $0.007 * *$ & 0.130 & 0.142 & $0.030^{*}$ & 0.770 & 0.563 & & & \\
\hline $8 \mathrm{MD}$ of the right & 0.082 & 0.045 & 0.097 & -0.070 & -0.017 & 0.012 & 0.083 & - & \\
\hline substantia nigra & $0.009 * *$ & 0.213 & 0.005 & 0.088 & 0.636 & 0.741 & 0.108 & & \\
\hline $9 \mathrm{MD}$ of the right & 0.069 & 0.049 & 0.047 & 0.005 & 0.014 & 0.077 & 0.021 & 0.358 & - \\
\hline hippocampus & $0.034^{*}$ & 0.165 & 0.165 & 0.908 & 0.671 & $0.032 *$ & 0.698 & $1.15 \times 10^{-30 * * *}$ & \\
\hline $10 \mathrm{MD}$ of the left & 0.068 & 0.040 & 0.049 & 0.002 & 0.020 & 0.073 & 0.017 & 0.367 & 0.983, \\
\hline
\end{tabular}

${ }^{*} \mathrm{p}<0.05, * * \mathrm{p}<0.01, * * * \mathrm{p}<0.001$

1 In the analyses of total gray matter volume, total intracranial volume was added as a covariate in addition to other covariates. To avoid double dipping procedure (Kriegeskorte et al., 2009), in the analyses for gray matter volume, total gray matter volume was used instead of regional gray matter volume of the cluster showing significant psychological and neuroimaging correlates of hair copper level. 


\section{Supplemental Table 3.}

Statistical results (beta value, $t$-value, uncorrected $p$-values) for the multiple regression analyses of the associations between hair iron level and dependent variables with or without subjects who are taking contraceptives.

\begin{tabular}{|c|c|c|c|c|c|c|}
\hline \multirow[b]{3}{*}{ Dependent variables } & \multicolumn{3}{|c|}{$\begin{array}{l}\text { Analyses using the same sample as } \\
\text { those of the main text }\end{array}$} & \multicolumn{3}{|c|}{$\begin{array}{c}\text { Analyses excluding subjects taking } \\
\text { contraceptives }\end{array}$} \\
\hline & $\beta$ & $t$ & $p$ & $\beta$ & $t$ & $p$ \\
\hline & & & rected) & & & (uncorrected) \\
\hline RAPM $^{\mathrm{a}}$ & -0.044 & -1.326 & 0.185 & -0.047 & -1.412 & 0.158 \\
\hline Total intelligence score of TBIT ${ }^{b}$ & -0.070 & -2.060 & 0.040 & -0.080 & -2.332 & 0.020 \\
\hline Perception score of TBIT & -0.066 & -1.884 & 0.060 & -0.077 & -2.200 & 0.028 \\
\hline Spatial relation factor of TBIT & -0.036 & -1.068 & 0.286 & -0.040 & -1.189 & 0.235 \\
\hline Reasoning factor of TBIT & -0.069 & -2.085 & 0.037 & -0.074 & -2.209 & 0.027 \\
\hline Simple arithmetic & -0.030 & -0.775 & 0.439 & -0.039 & -0.993 & 0.321 \\
\hline Complex arithmetic & -0.108 & -2.767 & 0.006 & -0.110 & -2.784 & 0.006 \\
\hline Reverse Stroop interference & -0.072 & -2.164 & 0.031 & -0.068 & -2.013 & 0.044 \\
\hline
\end{tabular}




$\begin{array}{lcccccr}\text { Stroop interference } & 0.044 & 1.318 & 0.188 & 0.043 & 1.265 & 0.206 \\ \text { Reading comprehension } & -0.074 & -2.114 & 0.035 & -0.079 & -2.229 & 0.026 \\ \text { S-A creativity test } & -0.049 & -1.483 & 0.138 & -0.051 & -1.517 & 0.130 \\ \text { Digit span } & -0.009 & -0.268 & & -0.013 & -0.390 & 0.697 \\ \text { POMS -Vigor } & -0.057 & -1.718 & 0.086 & -0.056 & -1.674 & 0.094 \\ \text { Extraversion } & -0.023 & -0.684 & 0.494 & -0.022 & -0.677 & 0.499 \\ \text { Novelty seeking } & 0.053 & 1.591 & 0.112 & 0.056 & 1.688 & 0.092 \\ \text { Total gray matter volume* } & 0.054 & 2.697 & 0.007 & 0.049 & 2.455 & 0.014 \\ \text { MD of the right substantia nigra } & 0.082 & 2.624 & 0.009 & 0.082 & 2.591 & 0.010 \\ \text { MD of the left substantia nigra } & -0.010 & -0.303 & 0.762 & -0.010 & -0.305 & 0.760 \\ \text { MD of the right hippocampus } & 0.069 & 2.127 & 0.034 & 0.065 & 2.006 & 0.045 \\ \text { MD of the left hippocampus } & 0.068 & 2.131 & 0.033 & 0.064 & 1.975 & 0.049\end{array}$

${ }^{\mathrm{a}}$ Raven's advanced progressive matrices (a general intelligence task). ${ }^{\mathrm{b}}$ Tanaka B-type intelligence test, ${ }^{\mathrm{c} P r o f i l e s ~ o f ~ M o o d ~ S t a t e s . ~}$ 
* In the analyses of total gray matter volume, total intracranial volume was added as a covariate in addition to other covariates. To avoid double dipping procedure (Kriegeskorte et al., 2009), in the analyses for gray matter volume, total gray matter volume was used instead of regional gray matter volume of the cluster showing significant psychological and neuroimaging correlates of hair copper level. 


\section{Supplemental Table 4.}

Statistical results (F-value, uncorrected p-values) for effects of the interactions between sex and hair copper levels by analyses of covariances

\begin{tabular}{lc}
$F$ & $p$ \\
& (uncorrected) \\
\hline 2.317 & 0.128 \\
0.803 & 0.370 \\
0.876 & 0.350 \\
0.954 & 0.329 \\
0.069 & 0.793 \\
0.178 & 0.673 \\
1.007 & 0.300 \\
1.320 & 0.250 \\
1.648 & 0.200 \\
0.909 & 0.341
\end{tabular}




$\begin{array}{lll}\text { S-A creativity test } & 0.137 & 0.711 \\ \text { Digit span } & 1.253 & \\ \text { POMS'-Vigor } & 2.063 & 0.263 \\ \text { Extraversion } & 1.343 & 0.247 \\ \text { Novelty seeking } & 0.189 & 0.664 \\ \text { Total gray matter volume* } & 1.938 & 0.164 \\ \text { MD of the right substantia nigra } & 0.009 & 0.926 \\ \text { MD of the left substantia nigra } & 0.130 & 0.718 \\ \text { MD of the right hippocampus } & 0.091 & 0.763 \\ \text { MD of the left hippocampus } & 0.017 & 0.895\end{array}$

$\overline{\mathrm{a}}$ Raven's advanced progressive matrices (a general intelligence task). ${ }^{\mathrm{b}}$ Tanaka B-type intelligence test, ${ }^{\mathrm{c}}$ Profiles of Mood States.

* In the analyses of total gray matter volume, total intracranial volume was added as a covariate in addition to other covariates. To avoid double dipping procedure (Kriegeskorte et al., 2009), in the analyses for gray matter volume, total gray matter volume was used instead of regional gray matter volume of the cluster showing significant psychological and neuroimaging correlates of hair copper level. 


\section{Supplemental figure legends.}

Supplemental Fig. 1. Histograms showing the logarithms of $\mathrm{Cu}$ levels in the hair for male and female subjects. 
Supplemental Fig. 1.

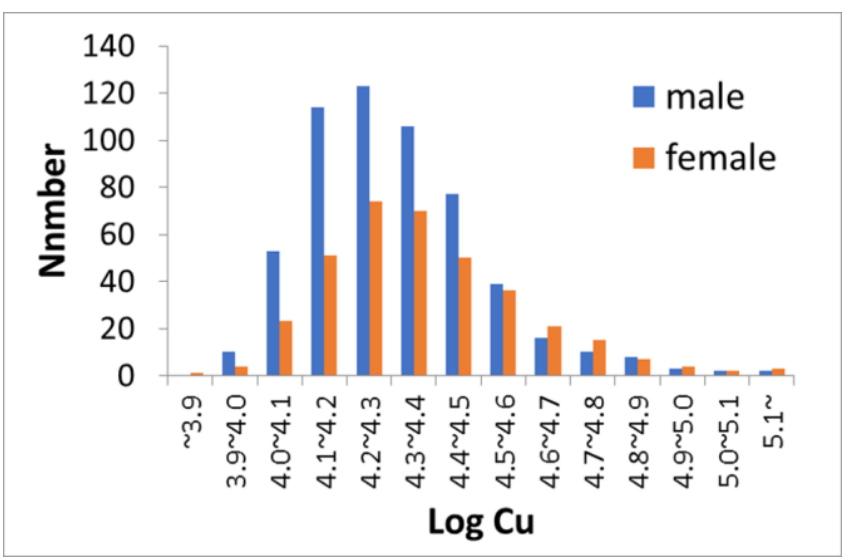




\section{References}

Ashburner J, Friston KJ (2000) Voxel-based morphometry-the methods. Neuroimage $11: 805-821$.

Barnea-Goraly N, Menon V, Eckert M, Tamm L, Bammer R, Karchemskiy A, Dant CC, Reiss AL (2005) White matter development during childhood and adolescence: a cross-sectional diffusion tensor imaging study. Cereb Cortex 15:1848-1854.

Cranton E, Bland J, Chatt A, Krakovitz R, Wright J (1982) Standardization and interpretation of human hair for elemental concentrations. Journal of Holistic Medicine 4:10-20.

Kriegeskorte N, Simmons WK, Bellgowan PS, Baker CI (2009) Circular analysis in systems neuroscience: the dangers of double dipping. Nat Neurosci 12:535-540.

Le Bihan D, Mangin JF, Poupon C, Clark CA, Pappata S, Molko N, Chabriat H (2001) Diffusion tensor imaging: concepts and applications. Journal of Magnetic Resonance Imaging 13:534-546.

Maldjian JA, Laurienti PJ, Burdette JH (2004) Precentral gyrus discrepancy in electronic versions of the Talairach atlas. Neuroimage 21:450-455.

Maldjian JA, Laurienti PJ, Kraft RA, Burdette JH (2003) An automated method for neuroanatomic and cytoarchitectonic atlas-based interrogation of fMRI data sets. Neuroimage 19:1233-1239.

Munakata M, Onuma A, Haginoya K, Kobayashi Y, Yokoyama H, Fujiwara I, Yasuda H, Tsutsui T, Iinuma K, Tsuchiya S (2006) Reduced exposure to mercury in patients receiving enteral nutrition. The Tohoku Journal of Experimental Medicine 210:209-212.

Takeuchi H, Taki Y, Sassa Y, Hashizume H, Sekiguchi A, Fukushima A, Kawashima R 
(2010a) White matter structures associated with creativity: Evidence from diffusion tensor imaging. Neuroimage 51:11-18.

Takeuchi H, Taki Y, Sassa Y, Hashizume H, Sekiguchi A, Fukushima A, Kawashima R (2011) Verbal working memory performance correlates with regional white matter structures in the fronto-parietal regions. Neuropsychologia 49:3466-3473

Takeuchi H, Sekiguchi A, Taki Y, Yokoyama S, Yomogida Y, Komuro N, Yamanouchi T, Suzuki S, Kawashima R (2010b) Training of Working Memory Impacts Structural Connectivity. J Neurosci 30:3297-3303.

Takeuchi H, Taki Y, Sassa Y, Hashizume H, Sekiguchi A, Nagase T, Nouchi R, Fukushima A, Kawashima R (2013a) White matter structures associated with emotional intelligence: Evidence from diffusion tensor imaging. Hum Brain Mapp 34:10251034.

Takeuchi H, Taki Y, Thyreau B, Sassa Y, Hashizume H, Sekiguchi A, Nagase T, Nouchi R, Fukushima A, Kawashima R (2013b) White matter structures associated with empathizing and systemizing in young adults. Neuroimage 77:222-236.

Takeuchi H, Taki Y, Nouchi R, Hashizume H, Sekiguchi A, Kotozaki Y, Nakagawa S, Miyauchi CM, Sassa Y, Kawashima R (2014) Effects of Multitasking-Training on Gray Matter Structure and Resting State Neural Mechanisms. Hum Brain Mapp 35:3646-3660.

Takeuchi H, Taki Y, Hashizume H, Asano K, Asano M, Sassa Y, Yokota S, Kotozaki Y, Nouchi R, Kawashima R (2016a) Impact of videogame play on the brain's microstructural properties: Cross-sectional and longitudinal analyses. Mol Psychiatry 21:1781-1789.

Takeuchi H, Taki Y, Sekiguchi A, Nouchi R, Kotozaki Y, Nakagawa S, Miyauchi CM, 
lizuka K, Yokoyama R, Shinada T (2016b) Mean diffusivity of basal ganglia and thalamus specifically associated with motivational states among mood states. Brain Struct Funct:1-11.

Takeuchi H, Taki Y, Nouchi R, Sekiguchi A, Hashizume H, Sassa Y, Kotozaki Y, Miyauchi CM, Yokoyama R, Iizuka K, Seishu N, Tomomi N, Kunitoki K, Kawashima R (2015) Degree centrality and fractional amplitude of low-frequency oscillations associated with Stroop interference. Neuroimage 119:197-209.

Takeuchi H, Taki Y, Sekiguchi A, Nouchi R, Kotozaki Y, Nakagawa S, Miyauchi CM, Iizuka K, Yokoyama R, Shinada T, Yamamoto Y, Hanawa S, Araki T, Hashizume H, Sassa Y, Kawashima R (2013c) Association of hair iron levels with creativity and psychological variables related to creativity. Frontiers in Human Neuroscience 7, Article 875:1-9.

Takeuchi H, Taki Y, Nouchi R, Yokoyama R, Kotozaki Y, Nakagawa S, Sekiguchi A, Iizuka K, Yamamoto Y, Hanawa S, Araki T, Miyauchi CM, Shinada T, Sakaki K, Sassa Y, Nozawa T, Ikeda S, Yokota S, Daniele M, Kawashima R (2017) Creative females have larger white matter structures: evidence from a large sample study. Hum Brain Mapp 38:414-430.

Taki Y, Thyreau B, Hashizume H, Sassa Y, Takeuchi H, Wu K, Kotozaki Y, Nouchi R, Asano M, Asano K (2013) Linear and curvilinear correlations of brain white matter volume, fractional anisotropy, and mean diffusivity with age using voxelbased and region of interest analyses in 246 healthy children. Hum Brain Mapp $34: 1842-1856$.

Yasuda H, Yoshida K, Yasuda Y, Tsutsui T (2011) Infantile zinc deficiency: association with autism spectrum disorders. Scientific reports 1:129. 
Yasuda H, Yoshida K, Yasuda Y, Tsuts T (2012) Two Age-Related Accumulation Profiles of Toxic Metals. Curr Aging Sci 5:105-111.

Yasuda H, Yonashiro T, Yoshida K, Ishii T, Tsutsui T (2005a) Mineral Imbalance in Children with Autistic Disorders. Biomedical research on trace elements 16:285292.

Yasuda H, Yonashiro T, Yoshida K, Ishii T, Tsutsui T (2005b) High toxic metal levels in scalp hair of infants and children. Biomed Res Trace Elem 16:39-45.

Yasuda H, Yoshida K, Fukuchi K, Tokuda R, Tsutsui T, Yonei Y (2007) Association between aging and minerals in male Japanese adults. Anti Aging Med 4:38-42.

Yasuda H, Yoshida K, Segawa M, Tokuda R, Yasuda Y, Tsutsui T (2008) High accumulation of aluminum in hairs of infants and children. Biomedical research on trace elements 19:57-62.

Yasuda H, Yoshida K, Segawa M, Tokuda R, Tsutsui T, Yasuda Y, Magara S (2009) Metallomics study using hair mineral analysis and multiple logistic regression analysis: relationship between cancer and minerals. Environ Health Prevent Med $14: 261-266$.

Yoshinaga J, Morita M, Okamoto K (1997) New human hair certified reference material for methylmercury and trace elements. Fresenius J Anal Chem 357:279-283. 